\title{
Sustained versus standard inflations during neonatal resuscitation to prevent mortality and improve respiratory outcomes (Review)
}

O’Donnell CPF, Bruschettini M, Davis PG, Morley CJ, Moja L, Calevo MG, Zappettini S

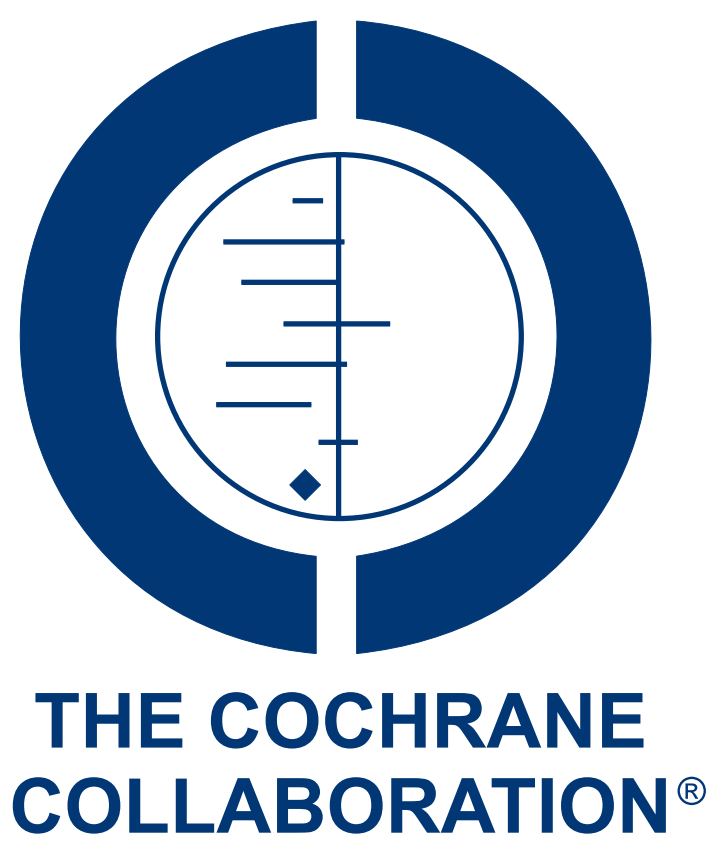

This is a reprint of a Cochrane review, prepared and maintained by The Cochrane Collaboration and published in The Cochrane Library 2015, Issue 7

http://www.thecochranelibrary.com

\section{WILEY}

Sustained versus standard inflations during neonatal resuscitation to prevent mortality and improve respiratory outcomes (Review) Copyright $\odot 2015$ The Cochrane Collaboration. Published by John Wiley \& Sons, Ltd. 
TABLE OF CONTENTS

HEADER

ABSTRACT

PLAIN LANGUAGE SUMMARY

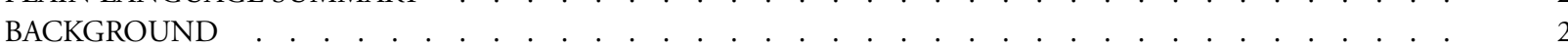

OBJECTIVES . . . . . . . . . . . . . . . . . . . . . . . . . . . . . . . . . . . . .

METHODS . . . . . . . . . . . . . . . . . . . . . . . . . . . . . . . . . . . . . . 3

RESULTS . . . . . . . . . . . . . . . . . . . . . . . . . . . . . . . . . . . . . . . 6

Figure 1. . . . . . . . . . . . . . . . . . . . . . . . . . . . . . . . . . . . 8

Figure 2. . . . . . . . . . . . . . . . . . . . . . . . . . . . . . . . . . . . . . 99

DISCUSSION . . . . . . . . . . . . . . . . . . . . . . . . . . . . . . . . . . . . . . . . .

AUTHORS' CONCLUSIONS . . . . . . . . . . . . . . . . . . . . . . . . . . . . . . . . . . . $\quad . \quad 11$

ACKNOWLEDGEMENTS . . . . . . . . . . . . . . . . . . . . . . . . . . . . . . . . . . . . . . 12

REFERENCES . . . . . . . . . . . . . . . . . . . . . . . . . . . . . . . . . . . . . . 12

CHARACTERISTICS OF STUDIES . . . . . . . . . . . . . . . . . . . . . . . . . . . . . . . . . . . . . .

DATA AND ANALYSES . . . . . . . . . . . . . . . . . . . . . . . . . . . . . . . . . . . . . 20

Analysis 1.1. Comparison 1 Use of initial sustained inflations vs. standard inflations in newborns receiving resuscitation, Outcome 1 Death.

Analysis 1.2. Comparison 1 Use of initial sustained inflations vs. standard inflations in newborns receiving resuscitation, Outcome 2 Apgar at $1 \mathrm{~min}$.

Analysis 1.3. Comparison 1 Use of initial sustained inflations vs. standard inflations in newborns receiving resuscitation, Outcome 3 Apgar at 5 mins.

Analysis 1.4. Comparison 1 Use of initial sustained inflations vs. standard inflations in newborns receiving resuscitation, Outcome 4 Endotracheal intubation.

Analysis 1.5. Comparison 1 Use of initial sustained inflations vs. standard inflations in newborns receiving resuscitation, Outcome 5 Surfactant administration.

Analysis 1.6. Comparison 1 Use of initial sustained inflations vs. standard inflations in newborns receiving resuscitation, Outcome 6 Need for mechanical ventilation.

Analysis 1.7. Comparison 1 Use of initial sustained inflations vs. standard inflations in newborns receiving resuscitation, Outcome 7 Duration of NCPAP.

Analysis 1.8. Comparison 1 Use of initial sustained inflations vs. standard inflations in newborns receiving resuscitation, Outcome 8 Duration of mechanical ventilation.

Analysis 1.9. Comparison 1 Use of initial sustained inflations vs. standard inflations in newborns receiving resuscitation, Outcome 9 Duration of respiratory support (NCPAP + MV).

Analysis 1.10. Comparison 1 Use of initial sustained inflations vs. standard inflations in newborns receiving resuscitation, Outcome 10 Chronic lung disease.

Analysis 1.11. Comparison 1 Use of initial sustained inflations vs. standard inflations in newborns receiving resuscitation, Outcome 11 Pneumothorax.

Analysis 1.12. Comparison 1 Use of initial sustained inflations vs. standard inflations in newborns receiving resuscitation, Outcome 12 Cranial ultrasound abnormalities.

Analysis 1.13. Comparison 1 Use of initial sustained inflations vs. standard inflations in newborns receiving resuscitation, Outcome 13 Retinopathy of prematurity (ROP).

Analysis 1.14. Comparison 1 Use of initial sustained inflations vs. standard inflations in newborns receiving resuscitation,

Outcome 14 Patent ductus arteriosus $(\mathrm{PDA}) . \quad$. . . . . . . . . . . . . . . . . . . . . . 30

HISTORY . . . . . . . . . . . . . . . . . . . . . . . . . . . . . . . . . . . . 30

CONTRIBUTIONS OF AUTHORS . . . . . . . . . . . . . . . . . . . . . . . . . . . . . . . . . . . . . .

DECLARATIONS OF INTEREST . . . . . . . . . . . . . . . . . . . . . . . . . . . . . . . . . . . . . .

SOURCES OF SUPPORT . . . . . . . . . . . . . . . . . . . . . . . . . . . . . . . . . . . . . . . . . . . . . . .

DIFFERENCES BETWEEN PROTOCOL AND REVIEW . . . . . . . . . . . . . . . . . . . . . . . . . . . .

Sustained versus standard inflations during neonatal resuscitation to prevent mortality and improve respiratory outcomes (Review)

Copyright $\odot 2015$ The Cochrane Collaboration. Published by John Wiley \& Sons, Ltd. 
[Intervention Review]

\title{
Sustained versus standard inflations during neonatal resuscitation to prevent mortality and improve respiratory outcomes
}

Colm PF O’Donnell ${ }^{1}$, Matteo Bruschettini ${ }^{2}$, Peter G Davis ${ }^{3}$, Colin J Morley ${ }^{4}$, Lorenzo Moja ${ }^{5}$, Maria Grazia Calevo ${ }^{6}$, Simona Zappettini 7

${ }^{1}$ Department of Neonatology, National Maternity Hospital, Dublin 2, Ireland. ${ }^{2}$ Neonatal Intensive Care Unit, Department of Pediatrics, Institute for Clinical Sciences, Lund University, Lund, Sweden. ${ }^{3}$ The University of Melbourne, Melbourne, Australia. ${ }^{4}$ Department of Obstetrics and Gynecology, University of Cambridge, Cambridge, UK. ${ }^{5}$ Department of Biomedical Sciences for Health, University of Milan, Milan, Italy. ${ }^{6}$ Epidemiology, Biostatistics and Committees Unit, Istituto Giannina Gaslini, Genoa, Italy. ${ }^{7}$ Health Regional Agency of the Liguria Region, Genoa, Italy

Contact address: Colm PF O’Donnell, Department of Neonatology, National Maternity Hospital, Holles Street, Dublin 2, Ireland. codonnell@nmh.ie.

Editorial group: Cochrane Neonatal Group.

Publication status and date: New, published in Issue 7, 2015.

Review content assessed as up-to-date: 1 February 2015.

Citation: O’Donnell CPF, Bruschettini M, Davis PG, Morley CJ, Moja L, Calevo MG, Zappettini S. Sustained versus standard inflations during neonatal resuscitation to prevent mortality and improve respiratory outcomes. Cochrane Database of Systematic Reviews 2015, Issue 7. Art. No.: CD004953. DOI: 10.1002/14651858.CD004953.pub2.

Copyright (C) 2015 The Cochrane Collaboration. Published by John Wiley \& Sons, Ltd.

\begin{abstract}
A B S T R A C T
Background

At birth, infants' lungs are fluid-filled; this fluid must be replaced by air to allow for effective breathing. Some infants are judged to have inadequate breathing at birth and are resuscitated with positive pressure ventilation (PPV). Giving prolonged (sustained) inflations at the start of PPV may help clear lung fluid and establish gas volume in the lungs.
\end{abstract}

Objectives

To assess the efficacy of initial sustained (> one second duration) lung inflation compared to standard inflations ( $\leq$ one second) in newly born infants receiving resuscitation with intermittent PPV.

Search methods

We searched on PubMed (1966 to 1 February 2015), EMBASE (1980 to 1 February 2015) and the Cochrane Central Register of Controlled Trials (the Cochrane Library 2015). No language restrictions were applied. We searched the abstracts of the Pediatric Academic Societies (PAS) from 2000 to 2014.

\section{Selection criteria}

Randomised controlled trials (RCTs) and quasi-RCTs comparing giving initial sustained lung inflations (SLI) vs. standard inflations to infants receiving resuscitation with PPV at birth.

Sustained versus standard inflations during neonatal resuscitation to prevent mortality and improve respiratory outcomes (Review)

Copyright @ 2015 The Cochrane Collaboration. Published by John Wiley \& Sons, Ltd. 


\section{Data collection and analysis}

We assessed methodological quality of the included trials using Cochrane Effective Practice and Organisation of Care Group (EPOC) criteria (assessing randomisation, blinding, loss to follow-up and handling of outcome data). We evaluated the treatment effect using a fixed-effect model using risk ratio for categorical data and using mean, standard deviation (SD) and weighted mean difference (WMD) for continuous data.

\section{Main results}

Two trials enrolling 352 infants met our inclusion criteria. There were no differences in the rates of mortality during hospitalisation (RR 1.59, 95\% CI 0.81 to 3.10; two trials, 352 infants), intubation in the first three days of life (RR 0.85 , 95\% CI 0.72 to 1.02 ; two trials, 352 infants) or chronic lung disease (RR 1.06, 95\% CI 0.79 to 1.42 ; two trials, 349 infants) between infants who received sustained versus standard inflations. The rate of patent ductus arteriosus (reported as need for pharmacological treatment) was higher in the sustained inflation group (RR 1.27, $95 \%$ CI 1.03 to 1.56; two trials, 352 infants).

\section{Authors' conclusions}

At present there is insufficient evidence from clinical trials to determine the efficacy and safety of initial sustained lung inflation for newborn infants resuscitated with PPV. RCTs comparing PPV with and without sustained inflations at neonatal resuscitation are warranted.

\section{PLAIN LANGUAGE SUMMARY}

\section{Prolonged lung inflation for neonatal resuscitation}

\section{Review question}

Does the use of sustained ( $>$ one second duration) lung inflations compared to standard inflations ( $\leq$ one second) improve survival and other important outcomes in newly born infants receiving resuscitation at birth?

\section{Background}

At birth, human lungs are filled with fluid which must be replaced by air for infants to breathe properly. Some infants have difficulty in establishing effective breathing at birth and one in every 20 to 30 newborns receive help to do so. A variety of devices are used to help infants begin their normal breathing. Some of these devices allow the caregivers to give long (or sustained) inflations. These sustained inflations may help inflate the lungs and keep the lungs inflated better than if they are not used.

\section{Study characteristics}

We searched for all randomised and quasi-randomised controlled trials that studied sustained inflation compared to standard inflations in neonatal resuscitation up to 1 Febuary 2015. Two RCTs enrolling 352 infants met our inclusion criteria.

\section{Results}

The two included trials provided insufficient evidence to determine if the risk of death during hospitalisation, intubation in the first three days of life, or chronic lung disease are different between infants who received sustained versus standard inflations. We assessed the quality of evidence using the Grading of Recommendations Assessment, Development and Evaluation (GRADE) approach. Several studies are ongoing.

\section{Description of the condition}


for effective respiration to occur. Most newly born infants achieve this spontaneously and may use considerable negative pressures (up to $-50 \mathrm{cmH} 2 \mathrm{O}$ ) for initial inspirations (Karlberg 1962; Milner 1977). However, it is estimated that $3 \%$ to $5 \%$ of newly born infants receive some help to breathe at delivery (Saugstad 1998). Adequate ventilation is the key to successful neonatal resuscitation and stabilisation (AHA 2010). Positive pressure ventilation (PPV) is recommended for infants who have absent or inadequate respiratory efforts and or bradycardia at birth (AHA 2010). The use of manual ventilation devices - self-inflating bags, flow-inflating (or anaesthetic) bags and T-piece devices - with a face mask or endotracheal tube (ETT) is advised. Though not described in "International Liaison Committee on Resuscitation" (ILCOR) guidelines, respiratory support of infants in the delivery room using a mechanical ventilator and nasopharyngeal tube has been described (Lindner 1999).

\section{Description of the intervention}

The devices recommended for PPV in the delivery room differ in their physical characteristics and ability to deliver sustained inflations. The most commonly used self-inflating bag (O'Donnell 2004a; O'Donnell 2004b) is of insufficient size to sustain an inflation > one second. Both flow-inflating bags and T-pieces may be used to deliver Inflations of $>$ one second. Although target inflation pressures and long inspiratory times are achieved more consistently in mechanical models when using T-piece devices than when using bags, no recommendation is made as to which device may be preferable (AHA 2010; ERC 2010).

\section{How the intervention might work}

Boon 1979 described a study of 20 term infants delivered by Caesarean section under general anaesthesia resuscitated with a $\mathrm{T}$ piece via an ETT. The trial authors reported that gas continued to flow through the flow sensor placed between the T-piece and ETT toward the infant at the end of a standard one second inflation on the respiratory traces they obtained (Boon 1979). Based on this observation, this group performed a non-randomised trial of giving sustained inflations with a T-piece and ETT to nine term infants during delivery room resuscitation. They reported that an initial five second inflation with a T-piece produced a two-fold increase in inflation volume compared to standard resuscitation techniques (Vyas 1981). Citing these studies, a retrospective cohort study described the effects of a change in management strategy of extremely low birth weight infants in the delivery room (Lindner 1999). The new management strategy included the introduction of an initial sustained inflation of 15 seconds with a mechanical ventilator via a nasopharyngeal tube. This change in strategy resulted in a reduction in the proportion of infants intubated for ongoing respiratory support without apparent increases in adverse outcomes. Interestingly, pulmonary morbidity in very low birth weight infants was reported to be related directly to mortality in $50 \%$ of the cases of deaths (Drew 1982). Moreover, multiple sustained inflations in very preterm infants improved both heart rate and cerebral tissue oxygen saturation, in absence of any detrimental effects (Fuchs 2011).

\section{Why it is important to do this review}

In the last few years the use of a sustained inflation at birth has been differently adopted by international recommendations. While European Resuscitation Council (ERC) guidelines suggest for the first few inflations to maintain the initial inflation pressure for two to three seconds (ERC 2010), the American Heart Association states that "there is insufficient evidence to recommend an optimum inflation time" (AHA 2010). A narrative review reported that it may reduce the need of mechanical ventilation in preterm infants at risk for respiratory distress syndrome (RDS) (Lista 2010). The same author showed that sustained inflation $(25 \mathrm{cmH} 2 \mathrm{O}$ for 15 seconds) improved respiratory outcomes compared to a historical group (Lista 2011).

\section{O B J E C T I V E S}

To assess the efficacy of giving initial sustained ( $>$ one second duration) inflations compared to standard inflations ( $\leq$ one second) in newborn infants receiving resuscitation with intermittent PPV.

\section{METHODS}

\section{Criteria for considering studies for this review}

\section{Types of studies}

Randomised controlled trials (RCTs) and quasi-RCTs. We excluded observational studies (case-control studies, case series) and cluster-RCTs.

\section{Types of participants}

Term and preterm infants resuscitated using PPV at birth.

\section{Types of interventions}

Resuscitation with initial sustained (> one second) inflations versus resuscitation with regular ( $\leq$ one second) inflations. 
Types of outcome measures

\section{Primary outcomes}

- Death in the delivery room.

- Death during hospitalisation.

- Death to latest follow-up.

\section{Secondary outcomes}

- Apgar scores at one and five minutes.

- Heart rate at five minutes.

- Endotracheal intubation in the delivery room.

- Endotracheal intubation outside the delivery room during hospitalisation.

- Surfactant administration in the delivery room or during hospital admission.

- Need for mechanical ventilation.

- Duration in hours of respiratory support, i.e. nasal continuous airway pressure and ventilation via an ETT considered separately and in total.

- Duration in days of supplemental oxygen requirement.

- Chronic lung disease: the need for supplemental oxygen at 28 days of life; the need for supplemental oxygen at 36 weeks gestational age for infants born at or before 32 weeks gestation.

- Air leaks (pneumothorax, pneumomediastinum, pneumopericardium, pulmonary interstitial emphysema) reported either individually or as a composite outcome.

- Cranial ultrasound abnormalities: any intraventricular haemorrhage (IVH), grade 3 or 4 (IVH) according to Papile classification (Papile 1978) and cystic periventricular leukomalacia.

- Seizures including clinical and electroencephalographic.

- Hypoxic ischaemic encephalopathy for term and late preterm infants (grade I-III - Sarnat 1976).

- Long-term neurodevelopmental outcome (rates of cerebral palsy on physician assessment, developmental delay, i.e. Intelligence Quotient (IQ) two standard deviations (SDs) < mean on validated assessment tools e.g. Bayley's Mental Developmental Index).

- Retinopathy of prematurity (ROP) (all stages and $\geq$ stage $3)$.

- Patent ductus arteriosus (PDA) (pharmacologic treatment and surgical ligation.

\section{Search methods for identification of studies}

See: Cochrane Neonatal Review Group (CNRG) search strategy.

\section{Electronic searches}

We searched the following electronic databases:

1. Cochrane Central Register of Controlled Trials (CENTRAL) in the Cochrane Library, 2015 Issue 2, using textwords "Infant, Newborn" and "sustained inflation".

2. MEDLINE (January 1996 to 1 February 2015): sustained[All Fields] AND “inflation"[All Fields] AND Clinical Trial[ptyp] AND “infant, newborn”[MeSH Terms].

3. EMBASE (January 1980 to 1 February 2015) using the limits Randomized Clinical Trial and newborn and the EMTREE terms "sustained” AND “inflat" AND "lung”/exp OR "lung" OR "pulmonary".

4. Abstracts of the Pediatric Academic Society (PAS) from 2000 to 2014 , electronically through the PAS web site ( abstractsonline) using the following key words: "sustained inflation" AND "clinical trial".

5. Perinatal Society of Australia and New Zealand (PSANZ). No language restrictions were applied.

\section{Searching other resources}

We searched for any ongoing or prospective trials in registries using the web sites of www.clinicaltrials.gov and www.controlledtrials.com. Also we checked for relevant articles in the list of references in articles located through electronic searches.

\section{Data collection and analysis}

\section{Selection of studies}

Three review authors (COD, PD, MB) independently screened all titles and abstracts to assess which trials met the inclusion criteria. We retrieved full text copies of all papers that were potentially relevant. Any disagreement was resolved by discussion between the review authors.

\section{Data extraction and management}

Two review authors (MB, COD) independently undertook data abstraction using a data extraction form developed ad hoc and integrated with a modified version of the Cochrane Effective Practice and Organisation of Care Group (EPOC) data collection checklist (EPOC 2015).

We extracted the following characteristics from each included trial:

- Administrative details: author(s); published or unpublished; year of publication; year in which trial was conducted; details of other relevant papers cited.

- Details of the trial: study design; type, duration and completeness of follow-up; country and location of study informed consent and ethics approval. 
- Details of participants: birth weight, gestational age and number of participants.

- Details of intervention: type of ventilation device used, type of interface, duration and level of pressure of the sustained inflation.

- Details of outcomes: Death during hospitalisation or to latest follow-up, heart rate at five minutes, duration in hours of respiratory support, duration in days of supplemental oxygen requirement, long-term neurodevelopmental outcomes and any adverse events.

We resolved any disagreements by discussion between the review authors. We described the ongoing trials identified, where available, detailing the primary author, research question(s), methods and outcome measures together with an estimate of the reporting date.

Where any queries arose or where additional data were required, we contacted the trial authors.

\section{Assessment of risk of bias in included studies}

Two review authors (MB, COD) independently assessed the methodological quality of all eligible trials using criteria described in the EPOC module. We resolved any discrepancies in quality ratings by discussion and involved an arbitrator where necessary. We used the standard quality criteria recommended by EPOC to assess the methodological limitations of trials (risk of bias) included in EPOC reviews.

The criteria for RCTs and quasi-RCTs were:

- Random sequence generation (selection bias).

- Allocation concealment (selection bias).

- Blinding of outcome assessment (detection bias).

- Incomplete outcome data (attrition bias).

- Selective reporting (reporting bias).

\section{Selection bias (random sequence generation and allocation concealment)}

For each included trial, we categorized the risk of selection bias as follows:

\section{Random sequence generation}

- Low risk - adequate (any truly random process e.g. random number table; computer random number generator);

- High risk - inadequate (any non random process e.g. odd or even date of birth; hospital or clinic record number);

- Unclear risk - no or unclear information provided.

\section{Allocation concealment}

For each included trial, we categorized the risk of bias regarding allocation concealment as:
- Low risk - adequate (e.g. telephone or central randomisation; consecutively numbered sealed opaque envelopes);

- High risk - inadequate (open random allocation; unsealed or non opaque envelopes, alternation; date of birth);

- Unclear risk - no or unclear information provided.

\section{Detection bias}

For each included trial, we categorized the methods used to blind outcome assessors from knowledge of which intervention a participant received. We assessed blinding separately for different outcomes or classes of outcomes.

\section{Attrition bias}

For each included trial and for each outcome, we described the completeness of data including attrition and exclusions from the analysis. We noted whether attrition and exclusions were reported, the numbers included in the analysis at each stage (compared with the total randomised participants), reasons for attrition or exclusion where reported, and whether missing data were balanced across groups or were related to outcomes.

\section{Reporting bias}

For each included trial, we described how we investigated the risk of selective outcome reporting bias and what we found. We assessed the methods as:

- Low risk - adequate (where it is clear that all of the trials' pre-specified outcomes and all expected outcomes of interest to the review have been reported);

- High risk - inadequate (where not all the trials' prespecified outcomes have been reported; one or more reported primary outcomes were not pre-specified; outcomes of interest are reported incompletely and so cannot be used; trial fails to include results of a key outcome that would have been expected to have been reported);

- Unclear risk - no or unclear information provided (the study protocol was not available).

\section{Other bias}

For each included trial, we described any important concerns we had about other possible sources of bias (e.g. whether there was a potential source of bias related to the specific trial design or whether the trial was stopped early due to some data dependent process). We assessed whether each trial was free of other problems that could put it at risk of bias as:

- Low risk - no concerns of other bias raised;

- High risk - concerns raised about multiple looks at the data with the results made known to the investigators, difference 
in number of patients enrolled in abstract and final publications of the paper;

- Unclear - concerns raised about potential sources of bias that could not be verified by contacting the trial authors.

We did not score blinding of the intervention because it was not applicable.

One review author entered data into RevMan 2014 and a second review author checked for data entry for accuracy.

\section{Measures of treatment effect}

We conducted measures of treatment effect data analysis using RevMan 2014. Outcome measures for dichotomous data (e.g. death, endotracheal intubation in the delivery room, frequency of retinopathy) were determined as a risk ratio (RR) with $95 \%$ confidence intervals (CIs). We calculated continuous data (e.g. duration of respiratory support, Apgar score) using the mean difference (MD) and SDs.

\section{Dealing with missing data}

In case of missing data, we contacted the trial authors to request missing data.

\section{Assessment of heterogeneity}

As a measure of consistency we used the $\mathrm{I}^{2}$ statistic and Q $\left(\mathrm{Chi}^{2}\right.$ test) (Deeks 2011). Statistical significance of the Q (Chi-squared) statistic was judged by $\mathrm{P}<0.10$ because of the low statistical power of the test. We used the following cut-offs for heterogeneity: <25\% no (none) heterogeneity; 25 to $49 \%$ low heterogeneity; 50 to $74 \%$ moderate heterogeneity; and $\geq 75 \%$ high heterogeneity (Higgins 2003). We combined the trials using the fixed-effect model, regardless of statistical evidence for heterogeneity effect sizes.

\section{Data synthesis}

We performed statistical analyses using RevMan 2014. We used the standard methods of the Cochrane Neonatal Review Group. For categorical data we used relative risk (RR), relative risk reduction, and absolute risk difference (RD). Mean and SD were obtained for continuous data and analysis performed using MD and weighted mean difference (WMD) when appropriate. We calculated $95 \%$ CIs. We presented the number needed to treat for an additional beneficial outcome (NNTB) and the number needed to treat for an additional harmful outcome (NNTH), as appropriate. For each comparison reviewed, meta-analysis could be feasible if more than one eligible trial was identified and there was sufficient homogeneity among the trials with respect to participants and interventions. We combined the trials using the fixed-effect model, regardless of statistical evidence for heterogeneity effect sizes. For estimates of RR and RD, we used the Mantel-Haenszel method.

\section{Subgroup analysis and investigation of heterogeneity}

We planned to perform the following subgroup analyses of the safety and efficacy of sustained inflations during resuscitation in subgroups:

- Of term ( $\geq 37$ weeks gestation) and preterm (<37 weeks) infants.

- Determined by the type of ventilation device used (self-

inflating bag, flow-inflating bag, T-piece, mechanical ventilator).

- Determined by the interface (i.e. face mask, ETT, nasopharyngeal tube) used.

- Determined by the duration of the sustained inflation (i.e. $>$ one second to five seconds, > five seconds).

\section{R E S U L T S}

\section{Description of studies}

See the Characteristics of included studies; Characteristics of excluded studies; Characteristics of ongoing studies; Characteristics of studies awaiting classification sections for details.

\section{Included studies}

Two trials recruiting 352 infants met the inclusion criteria (Lindner 2005; Lista 2015). We have listed the details of these trials in the Characteristics of included studies section.

Lindner 2005 was a single centre RCT considering newborns requiring resuscitation in the delivery room.

The median birth weight (range) was 870 (410 to 1320) g in the sustained inflations group and 830 (370 to 1370$) \mathrm{g}$ in the conventional (standard) group. The median gestational age (range) was 27.0 (25.0 to 28.9) weeks in the sustained inflations group and 26.7 (25.0 to 28.9 ) weeks in the conventional group.

Infants received support from a mechanical ventilator via a nasopharyngeal tube, fixed at $4 \mathrm{~cm}$ to $5 \mathrm{~cm}$. The mouth and the other nostril were closed by hand. Infants were randomised to receive either sustained inflation or nasal intermittent mandatory ventilation (NIMV), before starting nasal continuous positive airways pressure (NCPAP). Sustained inflation consisted of a 15 second inflation with peak inflation pressure (PIP) $20 \mathrm{cmH} 2 \mathrm{O}$, whereas NIMV was performed with the following parameters: PIP 20 $\mathrm{cmH} 2 \mathrm{O}$, positive end expiratory pressure (PEEP) 4 to $6 \mathrm{cmH} 2 \mathrm{O}$; inflation time 0.5 seconds; inflation rate 60 per minute). The infants were then supported with NCPAP at 4 to $6 \mathrm{cmH} 2 \mathrm{O}$. Infants in both groups who had apnoea on NCPAP could be treated with NIMV (PIP $20 \mathrm{cmH} 2 \mathrm{O}$; inflation time 0.3 seconds; inflation rate 60 per minute) for up to four minutes. Infants who did not respond satisfactorily in the sustained inflation group received up to two further 15 second inflations at higher inflating pressures 
( 25 and $30 \mathrm{cmH} 2 \mathrm{O}$ ). Infants whose response remained unsatisfactory were intubated and mechanically ventilated. Treatment was deemed to have failed if infants had persistently poor respiratory effort, bradycardia or cyanosis/low $\mathrm{SpO}_{2}$ in the delivery room; or if criteria combining clinical assessments of respiratory distress and evidence of impaired oxygenation, impaired ventilation (high $\mathrm{CO}_{2}$ ) or apnoea were met within 48 hours of birth.

Lista 2015 conducted a multicentre RCT of sustained lung inflation (SLI). Infants were included if they were born at $25+0$ weeks to $28+6$ weeks gestation and at high risk of RDS. Infants were excluded if they had fetal hydrops, major congenital malformation or inherited metabolic diseases. Infants were stratified by centre and to gestational age (GA). The sustained inflations group $(\mathrm{N}=148)$ received PIP of $25 \mathrm{cmH} 2 \mathrm{O}$ delivered for 15 seconds and then reduced to a PEEP of $5 \mathrm{cmH} 2 \mathrm{O}$. The control group ( $\mathrm{N}$ = 143) was resuscitated at birth according to American Academy of Pediatrics (AAP) guidelines without SLI manoeuvre. SLI and NCPAP were delivered by using a neonatal mask and a T-piece ventilator.

The primary endpoint was need of MV in the first $72 \mathrm{hrs}$ of life. Secondary endpoints were need and duration of any respiratory support and survival without bronchopulmonary dysplasia (BPD) at 36 weeks post GA. Significantly fewer infants were ventilated in the first 72 hours of life in the SLI group (79 of $148(53 \%)$ ) than in the control group (93 of $143(65 \%)$ ); unadjusted odds ratio: 0.62 (95\% CI 0.38 to $0.99 ; \mathrm{P}=0.04)$. The need for respiratory support and survival without BPD did not differ between the groups. Pneumothorax occurred in $1 \%(n=2)$ of infants in the control group compared with $6 \%(\mathrm{n}=9)$ in the SLI group, with an unadjusted odds ratio of 4.57 (95\% CI 0.97 to 21.50 ; $\mathrm{P}=0.06$ ).

\section{Excluded studies}

We have summarized the reasons for excluding potentially eligible trials (Bouziri 2011; Harling 2005; te Pas 2007) in the Characteristics of excluded studies table.

In particular, we excluded te Pas 2007 because sustained inflation was only one element of the intervention and it is not possible to determine the relative contribution of the various elements of this intervention to the differences observed between the groups. We excluded Harling 2005 as infants in this trial were randomised to receive a two second or five second inflation at the initiation of PPV. All infants thus received sustained (> one second) inflations as defined in our protocol (O’Donnell 2004).

\section{Risk of bias in included studies}

We have presented a summary of the 'Risk of bias' assessment in Figure 1 and Figure 2 Also, we have given details of the methodological quality of the included trials in the Characteristics of included studies section. 
Figure I. Risk of bias summary: review authors' judgements about each risk of bias item for each included trial.

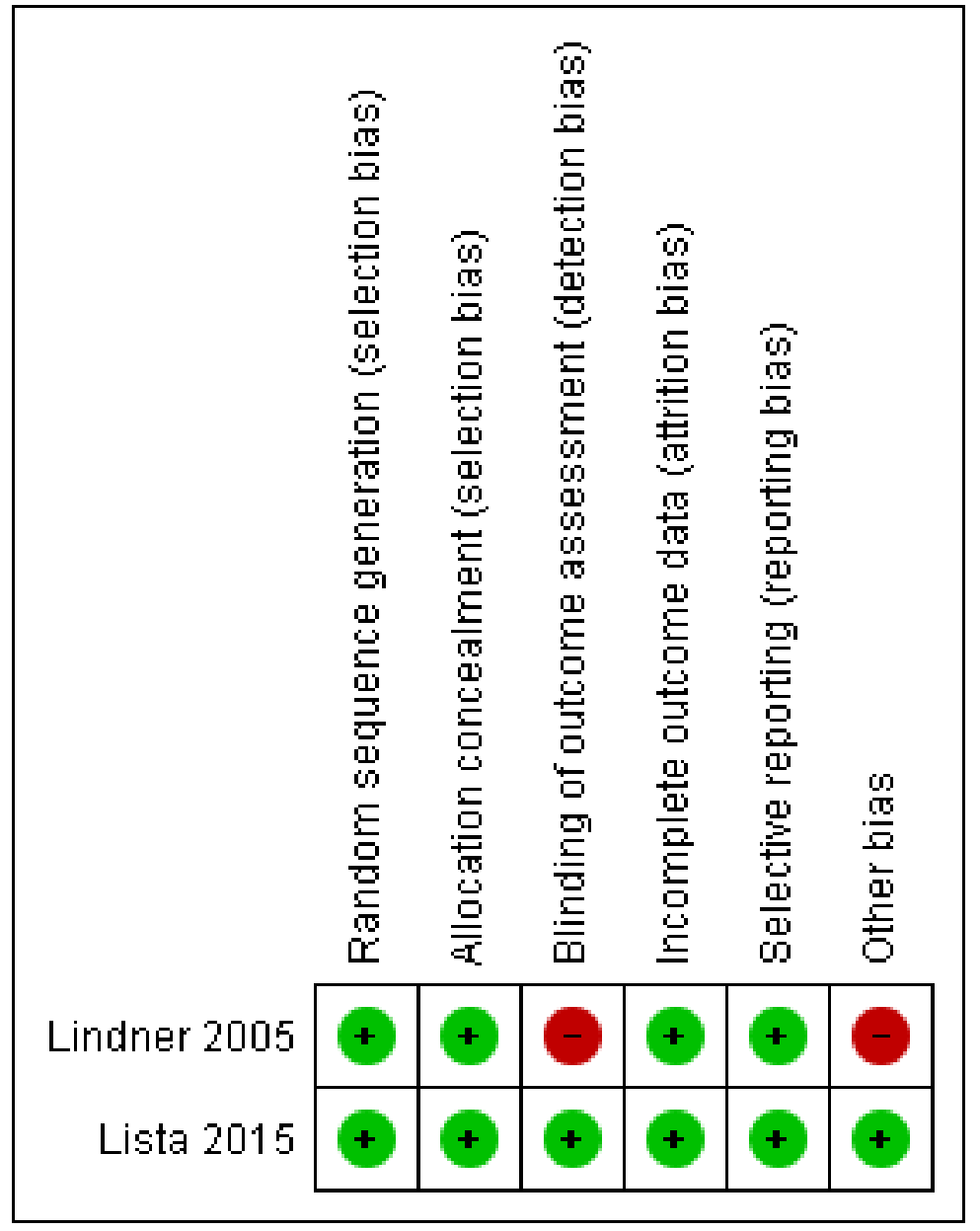


Figure 2. Risk of bias graph: review authors' judgements about each risk of bias item presented as percentages across all included trials.

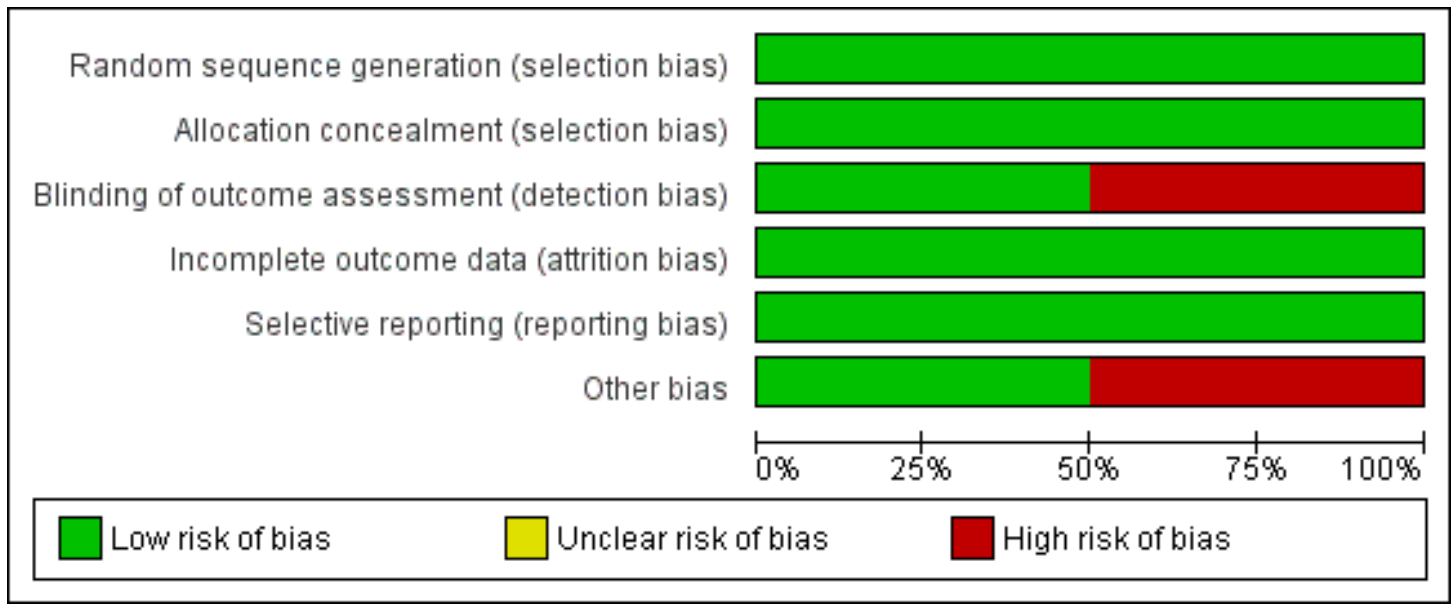

In both included trials (Lindner 2005; Lista 2015) the risk of selection bias was low (block randomisation was performed; stratification for gestational age and the method of allocation concealment were reported in detail (opaque, numbered envelopes)). Although the intervention was unblinded in both trials (leading to high potential for risk of bias), in Lista 2015 researchers assessing trial endpoints were blinded to the nature of the study treatments. Lindner 2005 was stopped after the interim analysis and presented unclear information about this decision.

We were unable to explore possible bias through funnel plots because only two trials met the inclusion criteria of this Cochrane review.

\section{Effects of interventions}

\section{Comparison: Use of initial sustained inflations vs. standard inflations in newborns receiving resuscitation}

\section{Primary outcomes}

\section{Death in the delivery room}

One trial $(\mathrm{N}=61)$ reported on this outcome, with no events (Lindner 2005). We obtained data for this outcome directly from the trial authors.

\section{Death during hospitalisation}

Both trials $(\mathrm{N}=352)$ reported on this outcome ( $\mathrm{RR} 1.59,95 \% \mathrm{CI}$ 0.81 to $3.10 ; \mathrm{I}^{2}$ statistic $=11 \%$; Analysis 1.1$)$. In Lindner 2005, the three deaths occurred in the sustained inflation group: at day 1 (respiratory failure), at day 36 (necrotizing enterocolitis) and day 107 (liver fibrosis of unknown origin). In Lista 201512 infants in the control group and 17 in the sustained inflations group died during the trial.

\section{Secondary outcomes}

\section{Apgar score at one minute}

One trial $(\mathrm{N}=61)$ reported on this outcome (MD 0.40, 95\% CI -0.55 to 1.35 ; test for heterogeneity was not applicable; Analysis 1.2). We obtained data for this outcome directly from the trial authors (Lindner 2005).

\section{Apgar score at five minutes}

One trial $(\mathrm{N}=61)$ reported on this outcome (MD 0.00, 95\% CI -1.00 to 1.00 ; the test for heterogeneity not applicable because only Lindner 2005 reported on this outcome; Analysis 1.3).

\section{Endotracheal intubation in the delivery room}

One trial $(\mathrm{N}=61)$ reported on this outcome $(\mathrm{RR} 1.38,95 \% \mathrm{CI}$ 0.61 to 3.16 ; the test for heterogeneity not applicable because only Lindner 2005 reported on this outcome; Analysis 1.4). 
Endotracheal intubation outside the delivery room during hospitalisation

Both included trials $(\mathrm{N}=352)$ reported on this outcome (RR $0.85,95 \%$ CI 0.72 to $1.02 ; \mathrm{I}^{2}$ statistic $=0$; Analysis 1.4). For both trials, data referred to 72 hours of life.

\section{Surfactant administration in the delivery room}

One trial $(\mathrm{N}=61)$ reported on this outcome $(\mathrm{RR} 1.74,95 \% \mathrm{CI}$ 0.66 to 4.60 ; the test for heterogeneity not applicable because only one trial (Lindner 2005) reported on this outcome; Analysis 1.5).

\section{Surfactant administration during hospital admission}

Both included trials $(\mathrm{N}=352)$ reported on this outcome ( $R R$ 0.97, 95\% CI 0.85 to $1.10 ; \mathrm{I}^{2}$ statistic $=0$; Analysis 1.5 ). For Lindner 2005, we obtained data for this outcome directly from the trial authors.

\section{Need for mechanical ventilation}

One trial $(\mathrm{N}=291)$ reported on this outcome (RR 0.87, 95\% CI 0.73 to 1.03 ; the test for heterogeneity not applicable because only one trial (Lista 2015) reported on this outcome; Analysis 1.6).

\section{Duration of nasal continuous airway pressure}

One trial $(\mathrm{N}=61)$ reported on this outcome (MD -5.40, 95\% CI -12.52 to 1.72 ; the test for heterogeneity not applicable; Analysis 1.7). We obtained data for this outcome directly from the trial authors and they refer to survivors at time of assessment (Lindner 2005).

\section{Duration of ventilation via an ETT}

One trial $(\mathrm{N}=61)$ reported on this outcome: MD 0.70, 95\% CI -9.23 to 10.63 , the test for heterogeneity was not applicable; Analysis 1.8). Data for this outcome refer to survivors at time of assessment (Lindner 2005).

Duration in hours of respiratory support (nasal continuous airway pressure and ventilation via an ETT, considered in total)

One trial $(\mathrm{N}=61)$ reported on this outcome (MD -4.80, 95\% CI -18.34 to 8.74 ; the test for heterogeneity not applicable; Analysis 1.9). We obtained data for this outcome were obtained directly from the trial authors and the data refer to survivors at time of assessment (Lindner 2005).
Chronic lung disease, i.e. the need for supplemental oxygen at 36 weeks gestational age for infants born at or before 32 weeks gestation

Both included trials $(\mathrm{N}=349)$ reported on this outcome ( $\mathrm{RR}$ $1.06,95 \%$ CI 0.79 to $1.42 ; \mathrm{I}^{2}$ statistic $=0$; Analysis 1.10$)$. For Lindner 2005, data for this outcome refer to survivors at time of assessment.

Air leaks (pneumothorax, pneumomediastinum, pneumopericardium, pulmonary interstitial emphysema) reported either individually or as a composite outcome

Both included trials $(\mathrm{N}=352)$ reported on this outcome ( $R R$ 1.93, $95 \%$ CI 0.75 to $5.01 ; \mathrm{I}^{2}$ statistic $=66 \%$; Analysis 1.11 ).

Any intraventricular haemorrhage (IVH), grade 3 or 4 (IVH) according to Papile classification (Papile 1978)

Both included trials $(\mathrm{N}=352)$ reported on this outcome (RR 1.45, $95 \%$ CI 0.67 to 3.14; $\mathrm{I}^{2}$ statistic $=0$; Analysis 1.12).

Cystic periventricular leukomalacia

Both trials $(\mathrm{N}=352)$ reported on this outcome ( $R R$ 0.32, $95 \%$ CI 0.09 to 1.15 ; $\mathrm{I}^{2}$ statistic $=0$; Analysis 1.12 ).

Rate of retinopathy of prematurity (ROP) $\geq$ stage 3

Both trials $(\mathrm{N}=349)$ reported on this outcome (RR 1.11, 95\% CI 0.60 to 2.06; $\mathrm{I}^{2}$ statistic $=0$; Analysis 1.13). For Lindner 2005, data refer to survivors at time of assessment.

Rate of PDA - pharmacological treatment

Both trials $(\mathrm{N}=352)$ reported on this outcome. There was a significant difference in rate of PDA (pharmacological treatment) favouring the standard inflation group (RR 1.27, 95\% CI 1.03 to 1.56; $\mathrm{I}^{2}$ statistic = 0; Analysis 1.14).

Rate of PDA - surgical closure

One trial $(\mathrm{N}=291)$ reported on this outcome (RR 0.60, 95\% CI 0.20 to 1.80 ; the test for heterogeneity not applicable (Lista 2015); Analysis 1.14)

The data refer to all randomised infants, unless differently specified.

No data were reported on the following outcomes: death to latest follow-up; heart rate; duration in days of supplemental oxygen requirement; need for supplemental oxygen at 28 days of life; seizures including clinical and electroencephalographic; hypoxic ischaemic encephalopathy in term and late preterm infants (grade I-III - Sarnat 1976); or long-term neurodevelopmental outcome. Subgroup analysis

We were unable to conduct any subgroup analysis as only we included only two trials.

\section{DISCUSSION}




\section{Summary of main results}

We evaluated the merits of sustained lung inflation compared to intermittent ventilation in infants requiring resuscitation and stabilisation at birth. Only two trials enrolling 352 preterm infants met the inclusion criteria (Lindner 2005; Lista 2015). Both trials enrolled infants $25^{+0}$ to $28^{+6}$ weeks. There was insufficient evidence to determine the efficacy and safety of sustained lung inflation compared to conventional inflations. However, the rate of PDA (reported as need for pharmacological treatment) was increased in the sustained lung inflation group. We identified three ongoing trials.

\section{Overall completeness and applicability of evidence}

To date, 352 newborns have been enrolled in two trials comparing the use of sustained versus standard inflations for initial resuscitation. Other larger trials are required to confirm the current evidence.

The three ongoing trials that we identified have important differences in the choice of gestational age (NCT01255826; NCT01739114; NCT02139800). NCT02139800 enrolls infants 23 to 26 weeks, NCT01255826 27 to 33 weeks, NCT01739114 $<34$ weeks. This discrepancy might prove to be important, as it has been reported that sustained inflation was more effective in infants of 28 to 30 weeks, as compared to either infants $<28$ or $>$ 30 weeks gestation (te Pas 2007).

There were insufficient data available to assess clinically important outcomes which were identified a priori. Outcomes such as death in the delivery room, heart rate, duration of supplemental oxygen requirement, and long-term neurodevelopmental outcome were not reported. Term infants were excluded. We could not perform a priori subgroup analysis (gestational age, ventilation device, interface, duration of the sustained inflation) to detect differential effects as there were only two included RCTs.

\section{Quality of the evidence}

We included only two trials in this Cochrane review. Lindner 2005 was stopped before target sample was recruited due to slow enrolment. The overall quality of the evidence was judged to be "low" due to the presence of detection and attrition bias. The more recent and larger trial, Lista 2015, was not affected by any relevant bias.

\section{Potential biases in the review process}

A major limitation to this Cochrane review was the definition of the sustained inflation as the trials used different duration and different pressure, which may have impacted on the results. None of the trials was blinded due to the nature of the intervention.

We excluded a potentially relevant trial, te Pas 2007, because sustained inflation was only one element of the intervention and it is not possible to determine the relative contribution of the various elements of this intervention to the differences observed between the two groups.

We excluded Harling 2005 because the control group consisted of a two seconds inflation (five seconds for intervention), whereas we defined sustained if $>$ one second.

\section{Agreements and disagreements with other studies or reviews}

One other systematic review of sustained lung inflation has been recently published (Schmölzer 2014). Schmölzer 2014 conducted a systematic review of randomised clinical trials comparing SLI versus IPPV as the primary respiratory intervention during respiratory support in preterm population $<33$ weeks gestational age in the delivery room. The review includes four trials, including two trials that we excluded from our systematic review (Harling 2005; te Pas 2007). Schmölzer 2014 reported a significant re-

duction in the need for mechanical ventilation within 72 hours after birth (typical relative risk $0.87,95 \%$ CI 0.77 to 0.97 ). As with our analysis, significantly more infants treated with SLI received treatment for PDA (RR 1.27, 95\% CI 1.05 to 1.54). There were no differences in BPD, death at the latest follow-up, and the combined outcome of death or BPD among survivors between the groups. Schmölzer 2014's findings differ from this Cochrane review because of the different definition of the duration of the intervention, and therefore in the determination of the included trials.

\section{A U THORS' CONCLUSIONS}

\section{Implications for practice}

There is insufficient evidence to establish the effects of sustained lung inflation for infants receiving respiratory support at birth. The optimal inflation time and inflation pressure required to establish an effective functional residual capacity in infants requiring resuscitation and stabilization in the delivery room remains to be determined.

\section{Implications for research}

RCTs of sustained lung inflation for infants receiving respiratory support at birth are warranted. These trials should aim to enrol infants who are at higher risk of these outcomes (i.e. preterm infants) 
and should be stratified by gestational age. Long-term neurodevelopmental outcomes (e.g. Bayley Scales of Infant Development administered at two years corrected age) should be measured.

\section{ACKNOWLEDGEMENTS}

We thank Drs Lindner, te Pas and Harling for their gracious assistance in providing extra data.

\section{R E F E R E N C E S}

\section{References to studies included in this review}

Lindner 2005 \{published data only\}

Lindner W, Högel J, Pohlandt F. Sustained pressurecontrolled inflation or intermittent mandatory ventilation in preterm infants in the delivery room? A randomized, controlled trial on initial respiratory support via nasopharyngeal tube. Acta Paediatrica 2005;94(3):303-9.

\section{Lista 2015 \{published data only\}}

Lista G, Boni L, Scopesi F, Mosca F, Trevisanuto D, Messner $\mathrm{H}$, et al. Sustained lung inflation at birth for preterm infants: a randomized clinical trial. Pediatrics 2015;135(2): e457-64.

\section{References to studies excluded from this review}

Bouziri 2011 \{published data only\}

Bouziri A, Hamdi A, Khaldi A, Bel Hadj S, Menif K, Ben Jaballah N. Management of meconium aspiration syndrome with high frequency oscillatory ventilation. La Tunisie Médicale 2011;89(7):632-7.

Harling 2005 \{published data only\}

Harling AE, Beresford MW, Vince GS, BAtes M, Yoxall $\mathrm{CW}$. Does sustained lung inflation at resuscitation reduce lung injury in the preterm infant?. Archives of Disease in Childhood. Fetal and Neonatal Edition 2005;90(5): F406-10.

te Pas 2007 \{published data only\} te Pas AB, Walther FJ. A randomized, controlled trial of delivery-room respiratory management in very preterm infants. Pediatrics 2007;120(2):322-9.

\section{References to ongoing studies}

NCT01255826 \{published data only\}

NCT01255826. Ventilatory management of the preterm neonate in the delivery room. clinicaltrials.gov/show/ NCT01255826 (accessed 1 February 2015).

NCT01739114 \{published data only\}

NCT01739114. Assessment of lung aeration at birth. clinicaltrials.gov/show/NCT01739114 (accessed 1 February 2015).
NCT02139800 \{published data only\}

NCT02139800. Sustained Aeration of Infant Lungs (SAIL) trial: study protocol for a randomized controlled trial. NCT02139800 (accessed 1 February 2015).

\section{Additional references}

\section{AHA 2010}

Kattwinkel J, Perlman JM, Aziz K, Colby C, Fairchild K, Gallagher J, et al. Part 15: neonatal resuscitation: 2010 American Heart Association Guidelines for Cardiopulmonary Resuscitation and Emergency Cardiovascular Care. Circulation 2010;122(18 Suppl 3): S909-19.

Boon 1979

Boon AW, Milner AD, Hopkin IE. Lung expansion, tidal exchange, and formation of the functional residual capacity during resuscitation of asphyxiated neonates. Journal of Pediatrics 1979;95(6):1031-6.

Deeks 2011

Deeks JJ, Higgins JPT, Altman DG (editors). Chapter 9: Analysing data and undertaking meta-analyses. In: Higgins JPT, Green S (editors). Cochrane Handbook for Systematic Reviews of Interventions Version 5.1.0 [updated March 2011]. The Cochrane Collaboration, 2011. Available from www.cochrane-handbook.org.

\section{Drew 1982}

Drew JH. Immediate intubation at birth of the very-lowbirth-weight infant. Effect on survival. American Journal of Diseases of Children 1982;136(3):207-10.

EPOC 2015

Effective Practice, Organisation of Care (EPOC). Cochrane EPOC Review Group data collection checklist. EPOC resources for review authors. Oslo: Norwegian Knowledge Centre for the Health Services; 2015. Available at: http:/ /epoc.cochrane.org/sites/epoc.cochrane.org/files/uploads/ datacollectionchecklist.pdf.

ERC 2010

Nolan JP, Soar J, Zideman DA, Biarent D, Bossaert LL, Deakin C, et al. European Resuscitation Council Guidelines for Resuscitation 2010 Section 1. Executive summary. Resuscitation 2010;81(10):1219-76. 


\section{Fuchs 2011}

Fuchs H, Lindner W, Buschko A, Trischberger T, Schmid M, Hummler HD. Cerebral oxygenation in very low birth weight infants supported with sustained lung inflations after birth. Pediatric Research 2011;70(2):176-80.

Higgins 2003

Higgins JPT, Thompson SG, Deeks JJ, Altman DG. Measuring inconsistency in meta-analyses. BMJ 2003;327 (7414):557-60.

Karlberg 1962

Karlberg P, Cherry RB, Escardó FE, Koc G. Respiratory studies in newborn infants. II: Pulmonary ventilation and mechanics of breathing in the first minutes of life, including the onset of respiration. Acta Paediatrica 1962;51(2): $121-36$.

Lindner 1999

Lindner W, Vossbeck S, Hummler H, Pohlandt F. Delivery room management of extremely low birth weight infants: spontaneous breathing or intubation. Pediatrics 1999;103 (5 Pt 1):961-7.

\section{Lista 2010}

Lista G, Castoldi F. Alveolar recruitment in the delivery room: sustained lung inflation [Reclutamento alveolare in sala parto: la sustained lung inflation]. Minerva Pediatrica 2010;62(3 Suppl 1):17-8

\section{Lista 2011}

Lista G, Fontana P, Castoldi F, Cavigioli F, Dani C. Does sustained lung inflation at birth improve outcome of preterm infants at risk for respiratory distress syndrome?. Neonatology 2011;99(1):45-50.

Milner 1977

Milner AD, Saunders RA. Pressure and volume changes during the first breath of human neonates. Archives of Disease in Childhood 1977;52(12):918-24.

O'Donnell 2004a

O'Donnell CPF, Davis PG, Morley CJ. Neonatal resuscitation: review of ventilation equipment and survey of practice in Australia and New Zealand. Journal of Paediatrics and Child Health 2004;40(4):208-12.

O’Donnell 2004b

O’Donnell CPF, Davis PG, Morley CJ. Positive pressure ventilation at neonatal resuscitation: review of equipment and international survey of practice. Acta Paediatrica 2004; 93(5):583-8.

\section{Papile 1978}

Papile LA, Burstein J, Burstein R, Koffler H. Incidence and evolution of subependymal and intraventricular hemorrhage: a study of infants with birth weights less than 1,500 gm. Journal of Pediatrics 1978;92(4):529-34.

\section{RevMan 2014}

The Nordic Cochrane Centre, The Cochrane Collaboration. Review Manager (RevMan). 5.3. Copenhagen: The Nordic Cochrane Centre, The Cochrane Collaboration, 2014.

Sarnat 1976

Sarnat HB, Sarnat MS. Neonatal encephalopathy following fetal distress. A clinical and electroencephalographic study. Archives of Neurology 1976;33(10):696-705.

\section{Saugstad 1998}

Saugstad OD. Practical aspects of resuscitating asphyxiated newborn infants. European Journal of Pediatrics 1998;157 (Suppl 1):S11-5.

\section{Schmölzer 2014}

Schmölzer GM, Kumar M, Aziz K, Pichler G, O’Reilly M, Lista $G$, et al. Sustained inflation versus positive pressure ventilation at birth: a systematic review and meta-analysis. Archives of Disease in Childhood. Fetal and Neonatal Edition 2014 Dec 30 [Epub ahead of print]. [DOI: 10.1136/archdischild-2014-306836]

Vyas 1981

Vyas H, Milner AD, Hopkin IE, Boon AW. Physiologic responses to prolonged and slow-rise inflation in the resuscitation of the asphyxiated newborn infant. Journal of Pediatrics 1981;99(4):635-9.

\section{References to other published versions of this review}

\section{O'Donnell 2004}

O'Donnell CPF, Davis PG, Morley CJ. Sustained inflations for neonatal resuscitation. Cochrane Database of Systematic Reviews 2004, Issue 4. [DOI: 10.1002/ 14651858.CD004953]

* Indicates the major publication for the study 


\section{CHARACTERISTICS OFSTUDIES}

\section{Characteristics of included studies [ordered by study ID]}

\section{Lindner 2005}

\begin{tabular}{|c|c|}
\hline Methods & RCT \\
\hline Participants & $\begin{array}{l}\text { Newly born infants } 25 \text { to } 28 \text { weeks gestation inclusive without malformations, oligo- } \\
\text { anhydramnios, } 20 \text { weeks gestation or feto-fetal transfusion syndrome, with respiratory } \\
\text { distress. A total of } 61 \text { infants were enrolled ( } 31 \text { in the sustained inflation group and } 30 \\
\text { in the control group) }\end{array}$ \\
\hline Interventions & $\begin{array}{l}\text { Sustained inflation or NIMV before starting NCPAP. Infants received support from a } \\
\text { mechanical ventilator via a nasopharyngeal tube; and were randomised to receive a } 15 \\
\text { second inflation with PIP } 20 \mathrm{cmH} 2 \mathrm{O} \text { or NIMV (PIP } 20 \mathrm{cmH} 2 \mathrm{O} \text {, PEEP } 4 \text { to } 6 \mathrm{cmH} 2 \mathrm{O} \text {; } \\
\text { inflation time } 0.5 \text { seconds; inflation rate } 60 \text { per minute) for } 30 \text { seconds prior to starting } \\
\text { NCPAP at } 4 \text { to } 6 \mathrm{cmH} 2 \mathrm{O} \text {. Infants in both groups who had apnoea on NCPAP could be } \\
\text { treated with NIMV (PIP } 20 \mathrm{cmH} 2 \mathrm{O} \text {; inflation time } 0.3 \text { seconds; inflation rate } 60 \text { per } \\
\text { minute) for up to } 4 \text { minutes. Infants who did not respond satisfactorily (persistent poor } \\
\text { or laboured respiratory effort, bradycardia or cyanosis and low oxygen saturation }\left(\mathrm{SpO}_{2} \text { ) }\right. \\
\text { ) in the sustained lung inflation group received up to two further } 15 \text { second inflations } \\
\text { at higher inflating pressures ( } 25 \text { and } 30 \mathrm{cmH} 2 \mathrm{O} \text { ). Infants whose response remained } \\
\text { unsatisfactory were intubated and mechanically ventilated. Treatment was deemed to } \\
\text { have failed if infants had persistently poor respiratory effort, bradycardia or cyanosis/ } \\
\text { low SpO } \mathrm{S}_{2} \text { in the the delivery room; or if criteria combining clinical assessments of } \\
\text { respiratory distress and evidence of impaired oxygenation, impaired ventilation (high } \\
\mathrm{CO}_{2} \text { ) or apnoea were met in within } 48 \text { hours of birth. }\end{array}$ \\
\hline
\end{tabular}

Outcomes Primary outcome: rate of infants reaching criteria for intubation and mechanical ventilation $<48$ hours of life

Secondary outcomes: mortality, Apgar score, endotracheal intubation, surfactant administration, duration of respiratory support, chronic lung disease, air leak, intraventricular haemorrhage, cystic periventricular leukomalacia, retinopathy of prematurity, PDA

Notes

Trial was stopped before target sample was recruited due to slow enrolment. Clinical outcomes were reported for all randomised infants

\section{Risk of bias}

\section{Bias}

Authors' judgement Support for judgement

Random sequence generation (selection Low risk bias)

Block randomised, stratified for gestational age (25 to 26 weeks, 27 to 28 weeks)

Allocation concealment (selection bias) Low risk Sealed opaque envelopes used.

Blinding of outcome assessment (detection High risk Unblinded intervention. bias)

All outcomes 
Lindner 2005 (Continued)

\begin{tabular}{l|l|l}
\hline $\begin{array}{l}\text { Incomplete outcome data (attrition bias) } \\
\text { All outcomes }\end{array}$ & Low risk & All infants accounted for. \\
\hline Selective reporting (reporting bias) & Low risk & All reported outcomes provided with complete results. \\
\hline Other bias & High risk & $\begin{array}{l}\text { The trial lacks of power because only } 61 \text { infants were enrolled } \\
\text { (instead of 110) }\end{array}$ \\
\hline
\end{tabular}

Lista 2015

\begin{tabular}{ll} 
Methods & $\begin{array}{l}\text { Multicentre prospective randomised parallel controlled trial } \\
\text { Infants were assigned immediately after birth before the first breath to receive either SLI } \\
\text { maneuvers and NCPAP or NCPAP alone in a } 1: 1 \text { ratio in permuted blocks of variable } \\
\text { size. Randomization was stratified according to centre and gestational age (25 or } 26 \\
\text { weeks and } 27 \text { or } 28 \text { weeks). Group assignment was contained in sequentially numbered, } \\
\text { sealed, opaque envelopes that were prepared by an independent statistician. The trial } \\
\text { was not blinded }\end{array}$ \\
\hline
\end{tabular}

Participants

Newly born infants 25 to 28 weeks gestation inclusive without major congenital malformations (i.e. congenital heart, cerebral, lung, abdominal malformations), fetal hydrops, and lack of parental consent. A total of 294 infants were enrolled (150 in the sustained lung inflation group and 144 in the control group)

Interventions

Infants in the SLI group underwent the following approach: after oropharyngeal and nasal suctioning, a pressure-controlled $\left(25 \mathrm{~cm} \mathrm{H}_{2} \mathrm{O}\right)$ inflation was sustained for 15 seconds, followed by the delivery of $5 \mathrm{~cm} \mathrm{H}_{2} \mathrm{O}$ CPAP, using a neonatal mask and Tpiece ventilator. Patients were observed for the next 6 to 10 seconds to evaluate their cardiorespiratory function. If respiratory failure persisted (i.e. apnoea, gasping) or the heart rate was 60 and 100 beats/min despite CPAP, the SLI maneuver (again $25 \mathrm{~cm} \mathrm{H}_{2} \mathrm{O}$ for 15 seconds) was repeated. If the heart rate remained 60 and 100 beats $/ \mathrm{min}$ after the second SLI maneuver, the infant was resuscitated following the guidelines of the AAP Infants in the control group were treated with NCPAP at $5 \mathrm{cmH} 2 \mathrm{O}$ and were assisted according to the guidelines of AAP. Infants in both groups who were not intubated in the delivery room were transferred to the NICU on NCPAP at $5 \mathrm{cmH} 2 \mathrm{O}$ with a fraction of inspired oxygen $\left(\mathrm{FiO}_{2}\right)$ of 0.21 to 0.40 (in agreement with local protocols).

Outcomes

Primary outcome: rate of infants reaching mechanical ventilation within the first 72 hours of life

Secondary outcomes: MV in the first 3 hours of life, highest $\mathrm{FiO}_{2}$, duration of NCPAP, need and duration of bilevel NCPAP, nasal IMV, conventional or high-frequency ventilation, duration of hospitalisation, need and number of doses of surfactant, occurrence of RDS, BPD, and mortality

Notes

Risk of bias

Bias

Authors' judgement

Support for judgement

Sustained versus standard inflations during neonatal resuscitation to prevent mortality and improve respiratory outcomes (Review)

Copyright $\odot 2015$ The Cochrane Collaboration. Published by John Wiley \& Sons, Ltd. 


\section{Lista 2015 (Continued)}

\begin{tabular}{l|l}
$\begin{array}{l}\text { Random sequence generation (selection Low risk } \\
\text { bias) }\end{array}$ & $\begin{array}{l}\text { Block randomised (1:1 ratio), stratified for } \\
\text { gestational age (25 to } 26 \text { weeks, and } 27 \text { to } \\
28 \text { weeks) }\end{array}$
\end{tabular}

28 weeks)

\begin{tabular}{|l|l|l}
\hline Allocation concealment (selection bias) & Low risk & $\begin{array}{l}\text { Group assignment was contained in se- } \\
\text { quentially numbered, sealed, opaque en- } \\
\text { velopes that were prepared by an indepen- } \\
\text { dent statistician and distributed to partici- } \\
\text { pating centres }\end{array}$
\end{tabular}

Blinding of outcome assessment (detection Low risk bias)

All outcomes

Unblinded intervention. Researchers assessing study endpoints were blinded to the nature of the study treatments

Incomplete outcome data (attrition bias) Low risk

Only $0.7 \%$ (control group) and $1.3 \%$ (SLI

All outcomes group) patients lost

\begin{tabular}{lll}
\hline Selective reporting (reporting bias) & Low risk & All outcomes reported for. \\
\hline Other bias & Low risk & Appears free of other bias. \\
\hline
\end{tabular}

Characteristics of excluded studies [ordered by study ID]

Study Reason for exclusion

Bouziri 2011 Not a clinical trial. Does not investigate sustained lung inflation

Harling 2005 The control group consisted of a two seconds inflation (five seconds for intervention): as we defined sustained if $>1$ second, this trial could not be included

Infants in the SLI group were born more preterm and had lower median birth weight than in conventional group, though the P value was not indicated. The median birth weight (range) was 885 (518 to 1460) g in the SLI group and 1095 (560 to 1562) $\mathrm{g}$ in the conventional group. The median gestational age (range) was 27 (23 to 30) weeks in the SLI group and 28 (23 to 31 ) weeks in the conventional group

te Pas 2007 This RCT enrolled newly born infants born at < 33 weeks gestation free of known major congenital anomalies with respiratory distress. Infants were randomised to a 10 second inflation at $20 \mathrm{cmH} 2 \mathrm{O}$ with a T-piece via a nasal tube or to intermittent PPV with a self-inflating bag via a face mask. Infants randomised to the T-piece received a 10 second inflation at $20 \mathrm{cmH} 2 \mathrm{O}$ followed by NCPAP at 5 to $6 \mathrm{cmH} 2 \mathrm{O}$. If the infant's clinical response was unsatisfactory, a further 10 second inflation at $25 \mathrm{cmH} 2 \mathrm{O}$ and NIMV (PIP 20 to $25 \mathrm{cmH} 2 \mathrm{O}$, inflation rate 60 per minute) could be given. If the infants' condition improved (satisfactory heart rate and colour) but they had irregular breathing, they could receive NIMV for several minutes. Infants who were judged to have inadequate breathing, remain bradycardic or remain cyanosed in the delivery room after these interventions were intubated and mechanically ventilated. Infants randomised to the self-inflating bag received initial inflations of 30 to $40 \mathrm{cmH} 2 \mathrm{O}$, followed by inflations not $>20$ $\mathrm{cmH} 2 \mathrm{O}$ (the inflation time was not specified or recorded) for 30 seconds. Infants who were judged to have inadequate breathing, remain bradycardic or remain cyanosed in the delivery room after this intervention were intubated and

Sustained versus standard inflations during neonatal resuscitation to prevent mortality and improve respiratory outcomes (Review) 
mechanically ventilated. Infants in the sustained lung inflation group who were not intubated were transferred to the neonatal intensive care unit (NICU) on NCPAP at 5 to $6 \mathrm{cmH} 2 \mathrm{O}$; non-intubated infants in the control group were transferred to the NICU with supplemental oxygen and monitored with pulse oximetry

The intervention in this trial was multifaceted. In addition to a sustained inflation, many other aspects of the respiratory care at birth differed between the groups (the ventilation device used; the interface used; whether PEEP was used; whether NIMV was used; the time allowed for stabilisation before intubation was considered; the time of starting NCPAP). It is not possible to determine the relative contribution (if any) of each element of this intervention to the differences in outcomes observed between the groups

\section{Characteristics of ongoing studies [ordered by study ID]}

\section{NCT01255826}

\begin{tabular}{|c|c|}
\hline Trial name or title & Ventilatory Management of the Preterm Neonate in the Delivery Room \\
\hline Methods & Multicenter prospective randomised parallel controlled trial. Masking: open label \\
\hline Participants & $\begin{array}{l}\text { Inclusion Criteria: Gestational age < } 34 \text { weeks. } \\
\text { Exclusion Criteria: Neonates with major congenital anomalies; Meconium aspiration syndrome, congenital } \\
\text { diaphragmatic hernia and anterior abdominal wall defect; Maternal chorioamnionitis; Neonates with gesta- } \\
\text { tional age }<26 \text { weeks or birth weight less than } 750 \text { grams }\end{array}$ \\
\hline Interventions & $\begin{array}{l}\text { SLI group: Pressure-controlled }(20 \mathrm{cmH} 2 \mathrm{O}) \text { inflation sustained for } 15 \text { seconds, using a neonatal mask and a } \\
\text { T-piece ventilator. This pressure controlled inflation will be followed by CPAP at } 5 \mathrm{cmH} 2 \mathrm{O} \text {. This procedure } \\
\text { will be repeated a second time with a pressure of } 25 \mathrm{cmH} 2 \mathrm{O} \text { for } 15 \text { seconds if breathing remained insufficient } \\
\text { and/or the heart rate is }<100 \mathrm{bpm} \text { and/or the infant is cyanotic. To be followed by CPAP at } 6 \mathrm{cmH} 2 \mathrm{O} \text {. A } \\
\text { third puff with a pressure of } 30 \mathrm{cmH} 2 \mathrm{O} \text { for } 15 \text { seconds will be used after few seconds if inadequate heart rate } \\
\text { and respiration was not reached. This will be followed by CPAP at } 7 \mathrm{cmH} 2 \mathrm{O} \\
\text { Control group: intermittent mask and bag ventilation, rate } 40-60 \text { per minute using a self-inflating bag and } \\
\text { mask with an oxygen reservoir }\end{array}$ \\
\hline Outcomes & $\begin{array}{l}\text { Primary outcomes: Need of endotracheal intubation after failure of positive pressure ventilation through face } \\
\text { mask in the delivery room (time frame: } 2 \text { minutes); Need for MV for neonates on NCPAP (time frame: } 28 \\
\text { days) } \\
\text { Secondary outcomes: Occurrence and duration of oxygen therapy; BPD; pulmonary air leak; PDA; NEC; } \\
\text { IVH; Neonatal sepsis; Length of NICU stay; Delivery room death or death during admission; Inflammatory } \\
\text { mediators before and after resuscitation }\end{array}$ \\
\hline Starting date & January 2011. \\
\hline Contact information & $\begin{array}{l}\text { Dina Mohamed Shinkar, MSc, 0020121524107, drdodi@hotmail.com } \\
\text { Gynecology and Obstetrics hospital, Ain-Shams University, Cairo, Egypt }\end{array}$ \\
\hline Notes & \\
\hline
\end{tabular}

Sustained versus standard inflations during neonatal resuscitation to prevent mortality and improve respiratory outcomes (Review) 


\begin{tabular}{|c|c|}
\hline Trial name or title & Assessment of Lung Aeration at Birth. \\
\hline Methods & Multicenter prospective randomised parallel controlled trial. Masking: Single Blind (Outcomes Assessor) \\
\hline Participants & $\begin{array}{l}\text { Inclusion Criteria: Infants }<33 \text { weeks gestation who require respiratory support for resuscitation in the delivery } \\
\text { room } \\
\text { Exclusion Criteria: congenital abnormality or condition that might have an adverse effect on breathing or } \\
\text { ventilation; absence of parents' consent to the study }\end{array}$ \\
\hline Interventions & $\begin{array}{l}\text { SLI group: Two initial sustained inflations with a PIP of } 20 \mathrm{cmH} 2 \mathrm{O} \text {, followed by a PEEP of } 5 \mathrm{cmH} 2 \mathrm{O} \text { and } \\
\text { then CPAP if breathing spontaneously or, if found to have apnoea or laboured breathing, mask IPPV with a } \\
\text { PIP of } 20 \mathrm{cmH} 2 \mathrm{O} \text { and PEEP of } 5 \mathrm{cmH} 2 \mathrm{O} \text { at a rate of } 40 \text { to } 60 \mathrm{bpm} \text {, at which time CPAP will be provided } \\
\text { Control group: Mask IPPV with an initial PIP of } 20 \mathrm{cmH} 2 \mathrm{O} \text { and PEEP of } 5 \mathrm{cmH} 2 \mathrm{O} \text {, and a ventilation rate } \\
\text { of } 40 \text { to } 60 \text { inflations/min until spontaneously breathing, at which time CPAP will be provided }\end{array}$ \\
\hline Outcomes & $\begin{array}{l}\text { Primary outcome: BPD } \\
\text { Secondary outcomes: Occurrence and duration of oxygen therapy; BPD; pulmonary air leak; PDA; NEC; } \\
\text { IVH; Neonatal sepsis; Length of NICU stay; Delivery room death or death during admission; Inflammatory } \\
\text { mediators before and after resuscitation. Need of endotracheal intubation after failure of positive pressure } \\
\text { ventilation through face mask in the delivery room (time frame: } 2 \text { minutes); Need for MV for neonates on } \\
\text { NCPAP (time frame: } 28 \text { days) }\end{array}$ \\
\hline Starting date & August 2013. \\
\hline Contact information & $\begin{array}{l}\text { Georg Schmolzer, MD,PhD, +1780 } 735 \text { ext 5179, georg.schmoelzer@me.com } \\
\text { University of Alberta. }\end{array}$ \\
\hline
\end{tabular}

\section{NCT02139800}

Trial name or title Sustained Aeration of Infant Lungs Trial (SAIL).

\begin{tabular}{ll}
\hline Methods & Two-arm randomized, controlled, multi-center clinical trial. \\
\hline Participants & $\begin{array}{l}\text { Infants of } 23-26 \text { weeks gestational age requiring respiratory support at birth. Sample size: } 600 \text { infants } \\
\text { Inclusion Criteria: Gestational age at least } 23 \text { weeks but less than } 27 \text { completed weeks by best obstetrical } \\
\text { estimate; Requiring resuscitation/respiratory intervention at birth } \\
\text { Exclusion Criteria: Considered non-viable by the attending neonatologist; Refusal of antenatal informed } \\
\text { consent; Known major anomalies, pulmonary hypoplasia; Mothers who are unable to consent for their medical } \\
\text { care and who do not have a surrogate guardian will not be approached for consent }\end{array}$ \\
\hline Interventions & $\begin{array}{l}\text { SLI group: sustained inflation in the delivery room. The first sustained inflation will use inflation pressure of } \\
20 \mathrm{cmH} 2 \mathrm{O} \text { for } 15 \text { seconds } \\
\text { Control group: CPAP of } 5-7 \mathrm{cmH} 2 \mathrm{O} \text { in the delivery room. }\end{array}$
\end{tabular}

Outcomes

Primary outcome: combined endpoint of death or BPD at 36 weeks gestational age

Secondary outcomes: Oxygen profile over first 24 hours; Oxygen profile with highest Fraction of Inspired

Sustained versus standard inflations during neonatal resuscitation to prevent mortality and improve respiratory outcomes (Review) 


\section{NCT02139800 (Continued)}

Oxygen $\left(\mathrm{FiO}_{2}\right)$ level up to 48 hours; Highest $\mathrm{FiO}_{2}$ level recorded during the first 48 hours; Heart rate in the Delivery Room (DR); Detailed status on departure from DR; Type of respiratory support (CPAP, PPV) and $\mathrm{FiO}_{2}$ on departure from DR; Use of inotropes on arrival in NICU; Circulatory support; Need for intubation in DR or by 24 hours of age; Pressure-volume characteristics in DR; Chest x-ray reports showing pneumothorax or new chest drains in the first 48 hours of life; Duration of any chest drain in-situ; Head ultrasound and/or MRI findings of intraventricular hemorrhage; Chest x-ray between days 7-10; Death or need for positive pressure ventilation at 7 days; Highest $\mathrm{FiO}_{2}$ and Area under the $\mathrm{FiO}_{2}$ curve for the first week of life; Pneumothorax and pulmonary interstitial emphysema (PIE); Survival to discharge home without $\mathrm{BPD}$, retinopathy of prematurity (grades $3 \& 4$ ), or significant brain abnormalities on head ultrasound; Duration of respiratory support (ventilation, CPAP, supplemental oxygen); Death in hospital; Retinopathy of prematurity (ROP) stage 3 or greater requiring treatment; Use of postnatal steroids for treatment of BPD; Length of hospital stay; Neurodevelopmental and respiratory outcome at 22-26 months corrected gestational age

Contact information Haresh Kirpalani, BM, MSc, kirpalanih@email.chop.edu Sarah J Ratcliffe, PhD, sratclif@upenn.edu.

Notes 
DATA ANDANALYSES

Comparison 1. Use of initial sustained inflations vs. standard inflations in newborns receiving resuscitation

\begin{tabular}{|c|c|c|c|c|}
\hline Outcome or subgroup title & $\begin{array}{l}\text { No. of } \\
\text { studies }\end{array}$ & $\begin{array}{c}\text { No. of } \\
\text { participants }\end{array}$ & Statistical method & Effect size \\
\hline 1 Death & 2 & & Risk Ratio (M-H, Fixed, 95\% CI) & Subtotals only \\
\hline $\begin{array}{l}\text { 1.1 Death in the delivery } \\
\text { room }\end{array}$ & 1 & 61 & Risk Ratio (M-H, Fixed, 95\% CI) & $0.0[0.0,0.0]$ \\
\hline 1.2 Death before discharge & 2 & 352 & Risk Ratio (M-H, Fixed, 95\% CI) & $1.59[0.81,3.10]$ \\
\hline 2 Apgar at $1 \mathrm{~min}$ & 1 & 61 & Mean Difference (IV, Fixed, 95\% CI) & $0.40[-0.55,1.35]$ \\
\hline 3 Apgar at 5 mins & 1 & 61 & Mean Difference (IV, Fixed, 95\% CI) & $0.0[-1.00,1.00]$ \\
\hline 4 Endotracheal intubation & 2 & & Risk Ratio (M-H, Fixed, 95\% CI) & Subtotals only \\
\hline $\begin{array}{l}\text { 4.1 Endotracheal intubation } \\
\text { in the delivery room }\end{array}$ & 1 & 61 & Risk Ratio (M-H, Fixed, 95\% CI) & $1.38[0.61,3.16]$ \\
\hline $\begin{array}{l}4.2 \text { Endotracheal intubation } \\
\text { by } 72 \text { hours of age }\end{array}$ & 2 & 352 & Risk Ratio (M-H, Fixed, 95\% CI) & $0.85[0.72,1.02]$ \\
\hline 5 Surfactant administration & 2 & & Risk Ratio (M-H, Fixed, 95\% CI) & Subtotals only \\
\hline $\begin{array}{l}5.1 \text { Surfactant given in the } \\
\text { delivery room }\end{array}$ & 1 & 61 & Risk Ratio (M-H, Fixed, 95\% CI) & $1.74[0.66,4.60]$ \\
\hline $\begin{array}{l}5.2 \text { Surfactant given at any } \\
\text { time }\end{array}$ & 2 & 352 & Risk Ratio (M-H, Fixed, 95\% CI) & $0.97[0.85,1.10]$ \\
\hline 6 Need for mechanical ventilation & 1 & & Risk Ratio (M-H, Fixed, 95\% CI) & Totals not selected \\
\hline 7 Duration of NCPAP & 1 & 58 & Mean Difference (IV, Fixed, 95\% CI) & $-5.40[-12.52,1.72]$ \\
\hline $\begin{array}{l}8 \text { Duration of mechanical } \\
\text { ventilation }\end{array}$ & 1 & 58 & Mean Difference (IV, Fixed, 95\% CI) & $0.70[-9.23,10.63]$ \\
\hline $\begin{array}{l}9 \text { Duration of respiratory support } \\
\text { (NCPAP + MV) }\end{array}$ & 1 & 58 & Mean Difference (IV, Fixed, 95\% CI) & $-4.80[-18.34,8.74]$ \\
\hline 10 Chronic lung disease & 2 & 349 & Risk Ratio (M-H, Fixed, 95\% CI) & $1.06[0.79,1.42]$ \\
\hline 11 Pneumothorax & 2 & 352 & Risk Ratio (M-H, Fixed, 95\% CI) & $1.93[0.75,5.01]$ \\
\hline $\begin{array}{l}12 \text { Cranial ultrasound } \\
\text { abnormalities }\end{array}$ & 2 & & Risk Ratio (M-H, Fixed, 95\% CI) & Subtotals only \\
\hline $\begin{array}{c}12.1 \text { Intraventricular } \\
\text { haemorrhage grade } 3-4\end{array}$ & 2 & 352 & Risk Ratio (M-H, Fixed, 95\% CI) & $1.45[0.67,3.14]$ \\
\hline $\begin{array}{l}\text { 12.2 Cystic periventricular } \\
\text { leukomalacia }\end{array}$ & 2 & 352 & Risk Ratio (M-H, Fixed, 95\% CI) & $0.32[0.09,1.15]$ \\
\hline $\begin{array}{l}13 \text { Retinopathy of prematurity } \\
\text { (ROP) }\end{array}$ & 2 & 349 & Risk Ratio (M-H, Fixed, 95\% CI) & $1.11[0.60,2.06]$ \\
\hline 14 Patent ductus arteriosus (PDA) & 2 & & Risk Ratio (M-H, Fixed, 95\% CI) & Subtotals only \\
\hline $\begin{array}{l}\text { 14.1 PDA - pharmacological } \\
\text { treatment }\end{array}$ & 2 & 352 & Risk Ratio (M-H, Fixed, 95\% CI) & $1.27[1.03,1.56]$ \\
\hline 14.2 PDA - surgical closure & 1 & 291 & Risk Ratio (M-H, Fixed, 95\% CI) & $0.60[0.20,1.80]$ \\
\hline
\end{tabular}

Sustained versus standard inflations during neonatal resuscitation to prevent mortality and improve respiratory outcomes (Review) 
Analysis I.I. Comparison I Use of initial sustained inflations vs. standard inflations in newborns receiving resuscitation, Outcome I Death.

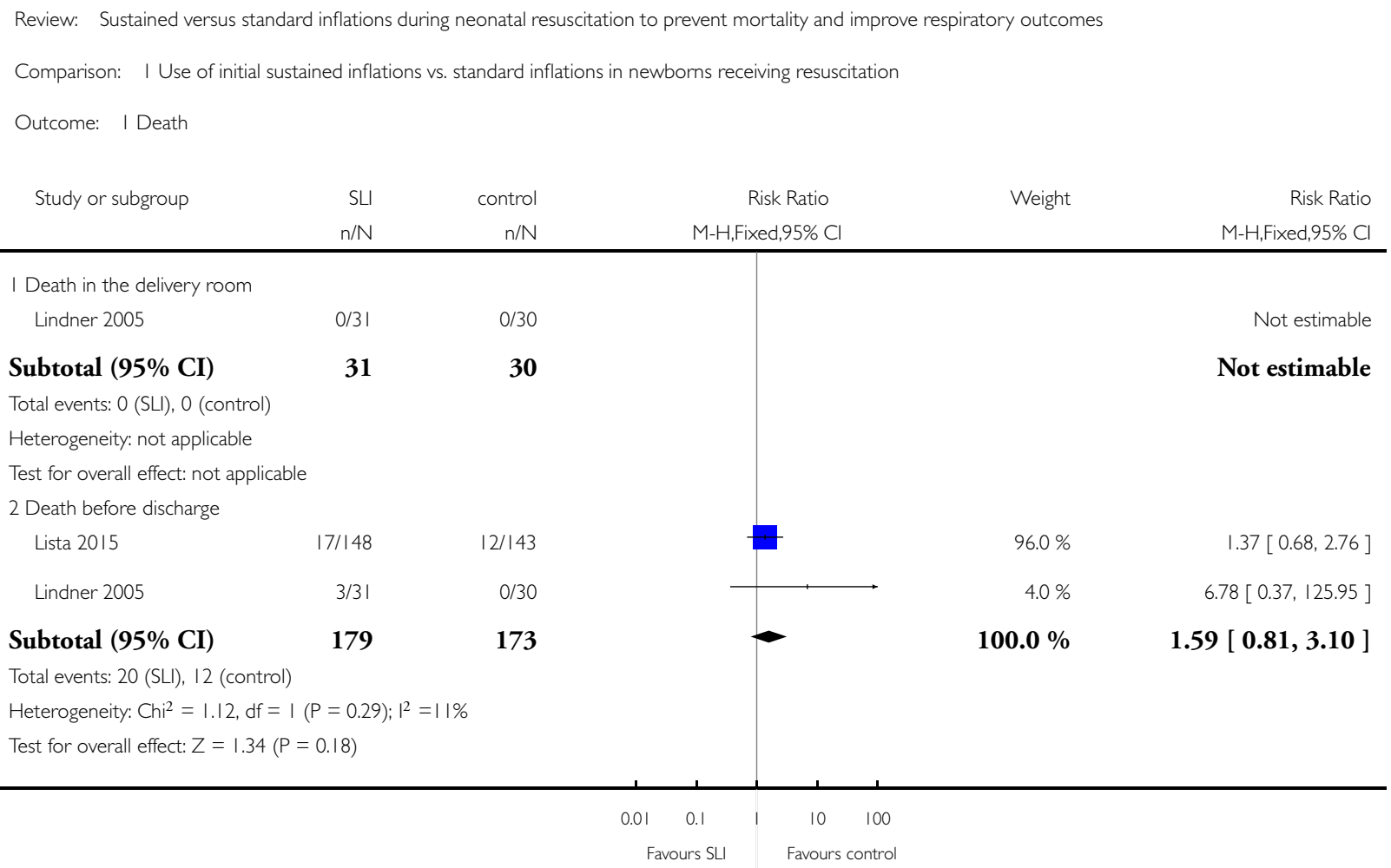


Analysis I.2. Comparison I Use of initial sustained inflations vs. standard inflations in newborns receiving resuscitation, Outcome 2 Apgar at I min.

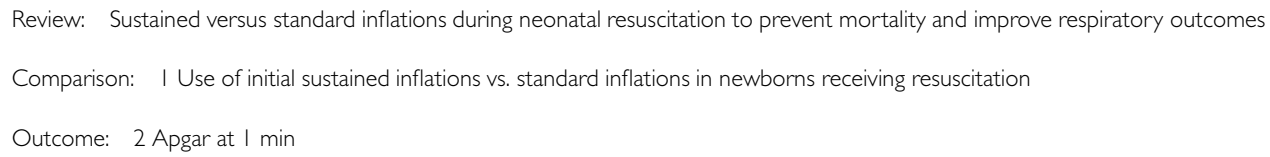

\begin{tabular}{ccccccc} 
Study or subgroup & SLI & & control & & $\begin{array}{c}\text { Mean } \\
\text { Difference } \\
\text { IV,Fixed,95\% Cl }\end{array}$ & $\begin{array}{c}\text { Mean } \\
\text { Difference }\end{array}$ \\
\hline Lindner 2005 & 31 & $4.2(1.9)$ & 30 & $3.8(1.9)$ & Mean(SD) & $100.0 \%$
\end{tabular}

Total $(95 \%$ CI $) \quad 31$

Heterogeneity: not applicable

Test for overall effect: $Z=0.82(P=0.4 I)$

Test for subgroup differences: Not applicable

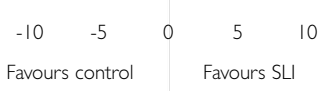

Analysis I.3. Comparison I Use of initial sustained inflations vs. standard inflations in newborns receiving resuscitation, Outcome 3 Apgar at 5 mins.

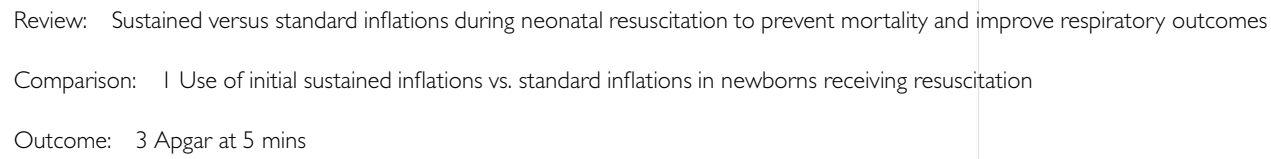

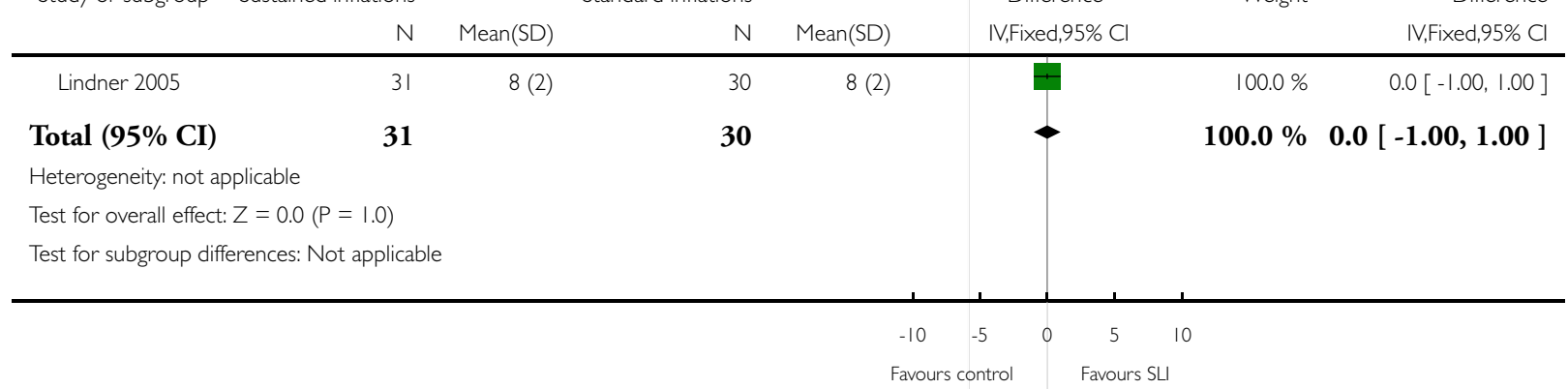


Analysis I.4. Comparison I Use of initial sustained inflations vs. standard inflations in newborns receiving resuscitation, Outcome 4 Endotracheal intubation.

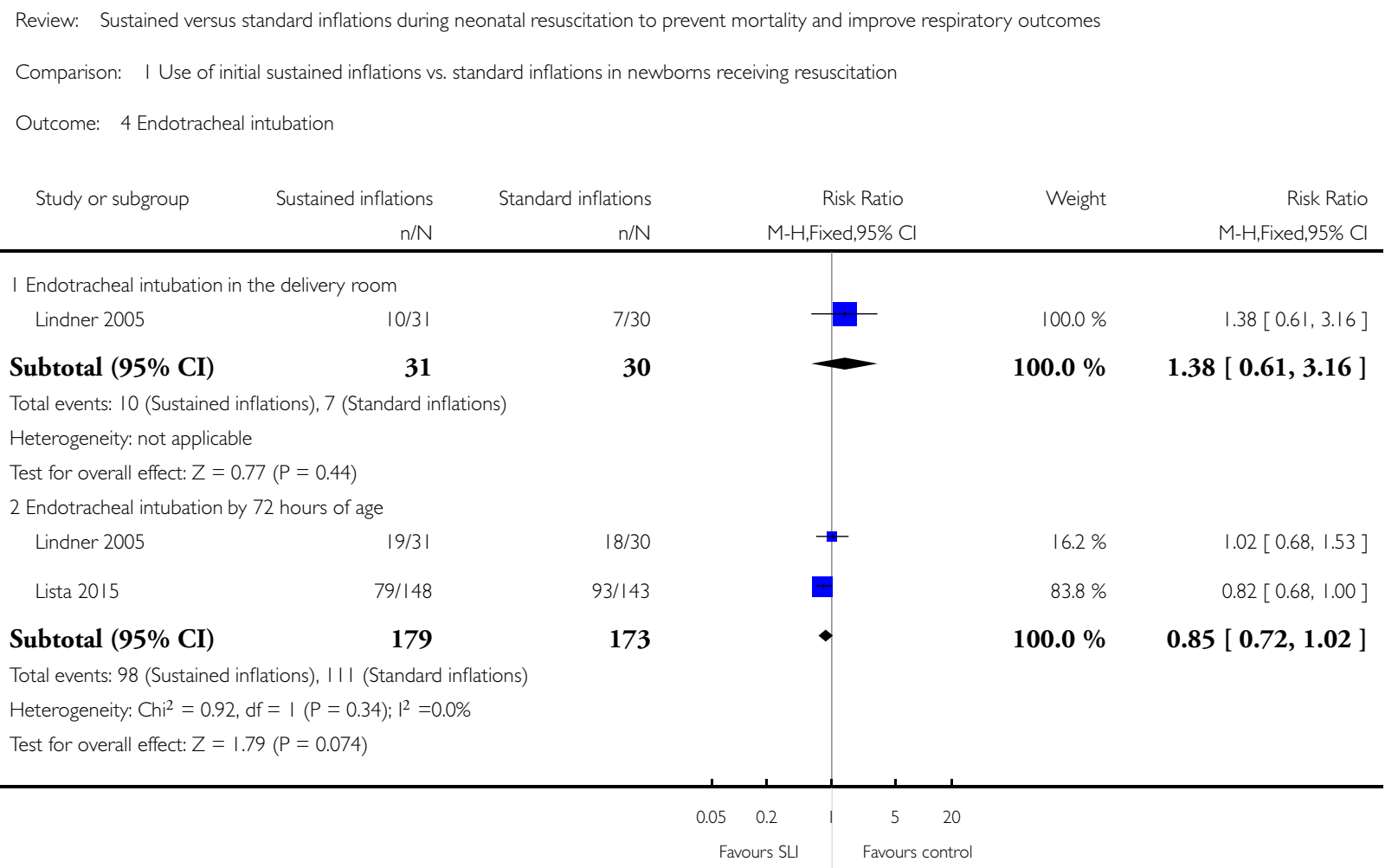


Analysis I.5. Comparison I Use of initial sustained inflations vs. standard inflations in newborns receiving resuscitation, Outcome 5 Surfactant administration.

\begin{tabular}{|c|c|c|c|c|c|}
\hline \multicolumn{6}{|c|}{ Comparison: I Use of initial sustained inflations vs. standard inflations in newborns receiving resuscitation } \\
\hline \multicolumn{6}{|c|}{ Outcome: 5 Surfactant administration } \\
\hline \multirow[t]{2}{*}{ Study or subgroup } & Sustained inflations & Standard inflations & Risk Ratio & Weight & Risk Ratio \\
\hline & $\mathrm{n} / \mathrm{N}$ & $\mathrm{n} / \mathrm{N}$ & M-H,Fixed,95\% Cl & & $\mathrm{M}-\mathrm{H}$, Fixed,95\% Cl \\
\hline \multicolumn{6}{|c|}{ I Surfactant given in the delivery room } \\
\hline Lindner 2005 & $9 / 31$ & $5 / 30$ & & $100.0 \%$ & $1.74[0.66,4.60]$ \\
\hline Subtotal $(95 \%$ CI $)$ & 31 & 30 & & $100.0 \%$ & $1.74[0.66,4.60]$ \\
\hline \multicolumn{6}{|c|}{ Total events: 9 (Sustained inflations), 5 (Standard inflations) } \\
\hline \multicolumn{6}{|c|}{ Heterogeneity: not applicable } \\
\hline \multicolumn{6}{|c|}{ Test for overall effect: $Z=1.12(P=0.26)$} \\
\hline \multicolumn{6}{|c|}{2 Surfactant given at any time } \\
\hline Lindner 2005 & $|8 / 3|$ & $17 / 30$ & $\rightarrow$ & $13.4 \%$ & $1.02[0.66,1.58]$ \\
\hline Lista 2015 & $109 / 148$ & $110 / 143$ & E & $86.6 \%$ & $0.96[0.84,1.09]$ \\
\hline Subtotal $(95 \%$ CI $)$ & 179 & 173 & 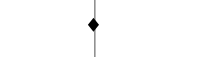 & $100.0 \%$ & $0.97[0.85,1.10]$ \\
\hline \multicolumn{6}{|c|}{ Total events: 127 (Sustained inflations), 127 (Standard inflations) } \\
\hline \multicolumn{6}{|c|}{ Heterogeneity: $\mathrm{Ch}^{2}=0.09, \mathrm{df}=\mathrm{I}(\mathrm{P}=0.76) ; \mathrm{I}^{2}=0.0 \%$} \\
\hline \multicolumn{6}{|c|}{ Test for overall effect: $Z=0.52(P=0.60)$} \\
\hline Test for subgroup differenc & $h i^{2}=1.39, d f=I(P$ & $4), I^{2}=28 \%$ & & & \\
\hline
\end{tabular}

Analysis I.6. Comparison I Use of initial sustained inflations vs. standard inflations in newborns receiving resuscitation, Outcome 6 Need for mechanical ventilation.

Review: Sustained versus standard inflations during neonatal resuscitation to prevent mortality and improve respiratory outcomes

Comparison: I Use of initial sustained inflations vs. standard inflations in newborns receiving resuscitation

Outcome: 6 Need for mechanical ventilation

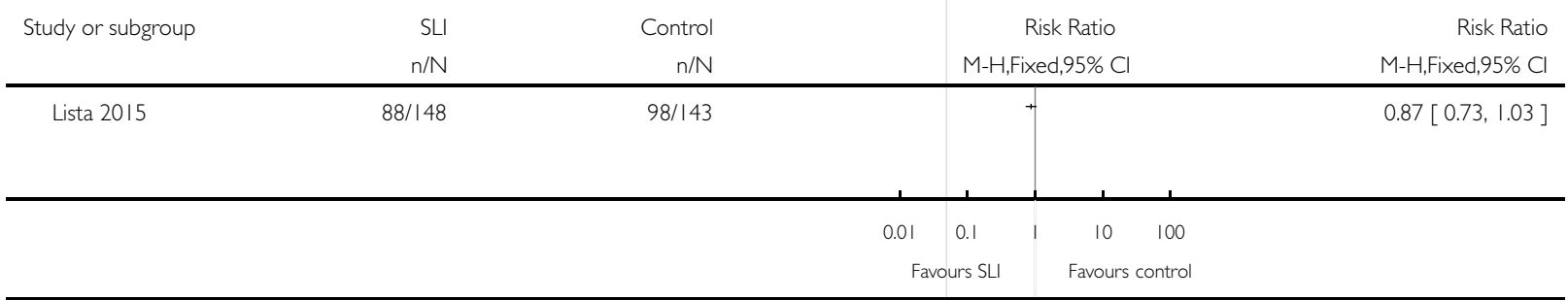

Sustained versus standard inflations during neonatal resuscitation to prevent mortality and improve respiratory outcomes (Review) 


\section{Analysis I.7. Comparison I Use of initial sustained inflations vs. standard inflations in newborns receiving}

resuscitation, Outcome 7 Duration of NCPAP.

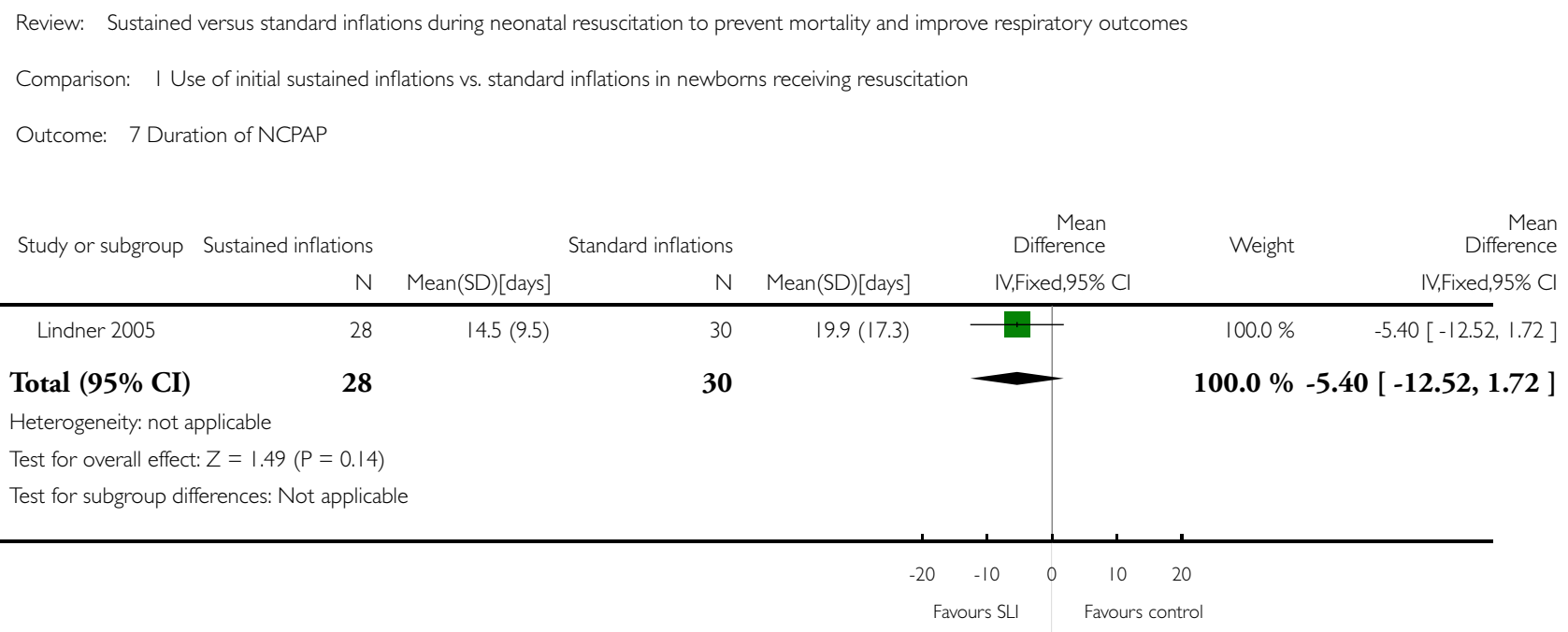


Analysis I.8. Comparison I Use of initial sustained inflations vs. standard inflations in newborns receiving resuscitation, Outcome 8 Duration of mechanical ventilation.

Review: Sustained versus standard inflations during neonatal resuscitation to prevent mortality and improve respiratory outcomes

Comparison: I Use of initial sustained inflations vs. standard inflations in newborns receiving resuscitation

Outcome: 8 Duration of mechanical ventilation

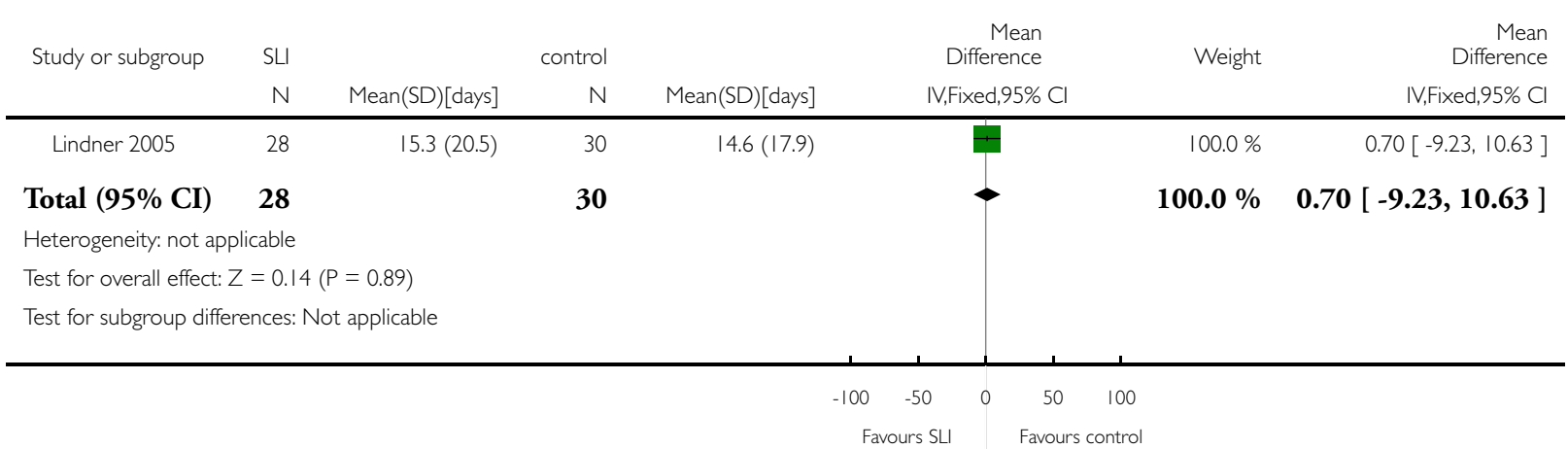

Analysis I.9. Comparison I Use of initial sustained inflations vs. standard inflations in newborns receiving resuscitation, Outcome 9 Duration of respiratory support (NCPAP + MV).

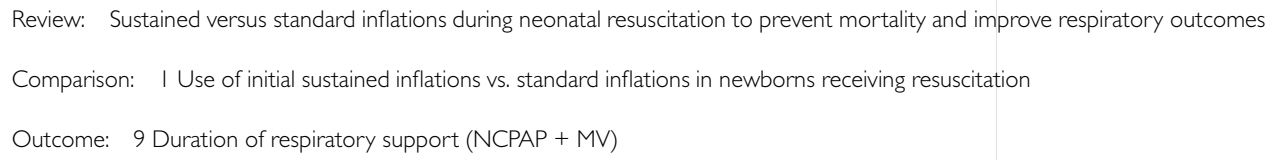

Total (95\% CI)

Heterogeneity: not applicable 
Analysis I.I0. Comparison I Use of initial sustained inflations vs. standard inflations in newborns receiving resuscitation, Outcome 10 Chronic lung disease.

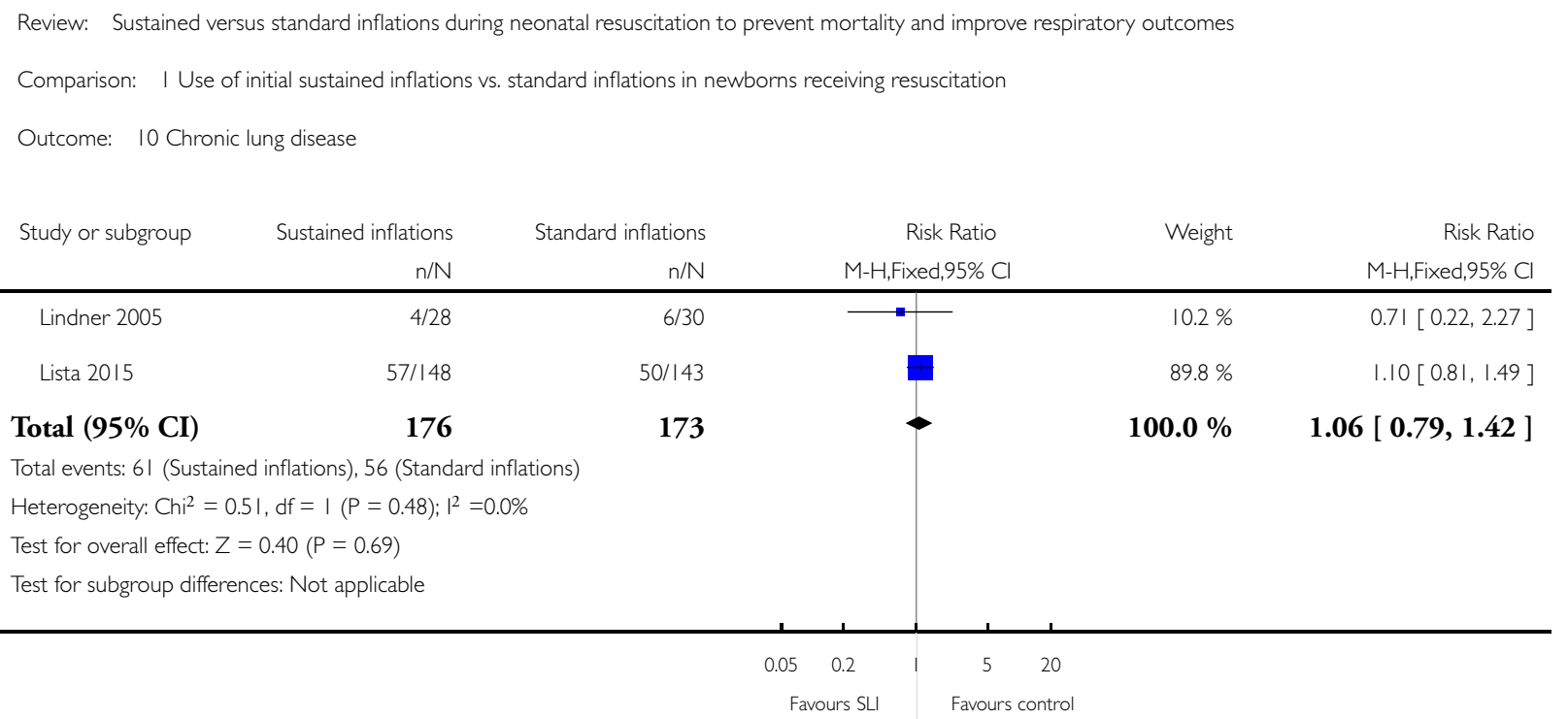

\section{Analysis I.I I. Comparison I Use of initial sustained inflations vs. standard inflations in newborns receiving} resuscitation, Outcome I I Pneumothorax.

\footnotetext{
Review: Sustained versus standard inflations during neonatal resuscitation to prevent mortality and improve respiratory outcomes

Comparison: I Use of initial sustained inflations vs. standard inflations in newborns receiving resuscitation

Outcome: II Pneumothorax
}

\begin{tabular}{|c|c|c|c|c|c|c|}
\hline \multirow[t]{2}{*}{ Study or subgroup } & \multirow{2}{*}{$\begin{array}{r}\text { Sustained inflations } \\
n / N\end{array}$} & \multicolumn{2}{|l|}{ Standard inflations } & Risk Ratio & \multirow[t]{2}{*}{ Weight } & \multirow{2}{*}{$\begin{array}{r}\text { Risk Ratio } \\
\text { M-H,Fixed,95\% Cl }\end{array}$} \\
\hline & & $\mathrm{n} / \mathrm{N}$ & & M-H,Fixed,95\% Cl & & \\
\hline Lindner 2005 & $3 / 31$ & $4 / 30$ & & $\square$ & $66.6 \%$ & $0.73[0.18,2.97]$ \\
\hline Lista 2015 & $9 / 148$ & $2 / 143$ & & & $33.4 \%$ & $4.35[0.96,19.78]$ \\
\hline Total $(95 \% \mathrm{CI})$ & 179 & 173 & & - & $100.0 \%$ & $1.93[0.75,5.01]$ \\
\hline \multicolumn{7}{|c|}{ Total events: 12 (Sustained inflations), 6 (Standard inflations) } \\
\hline \multicolumn{7}{|c|}{ Heterogeneity: Chi $^{2}=2.95, d f=1(P=0.09) ;\left.\right|^{2}=66 \%$} \\
\hline \multicolumn{7}{|c|}{ Test for overall effect: $Z=1.36(P=0.17)$} \\
\hline \multicolumn{7}{|c|}{ Test for subgroup differences: Not applicable } \\
\hline & & & 0.05 & 0.2 & 20 & \\
\hline & & & & Favours & ntrol & \\
\hline
\end{tabular}

Sustained versus standard inflations during neonatal resuscitation to prevent mortality and improve respiratory outcomes (Review) 


\section{Analysis I.I2. Comparison I Use of initial sustained inflations vs. standard inflations in newborns receiving} resuscitation, Outcome 12 Cranial ultrasound abnormalities.

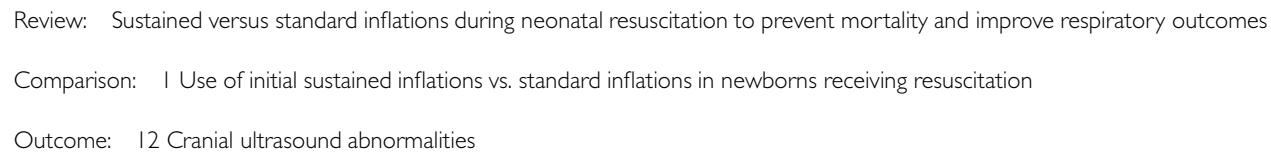

$$
\text { Lista } 2015
$$

$12 / 148$

Subtotal (95\% CI)

179

Total events: 15 (Sustained inflations), 10 (Standard inflations)

Heterogeneity: Chi $^{2}=0.00, \mathrm{df}=1(P=1.00) ; \mathrm{I}^{2}=0.0 \%$

Test for overall effect: $Z=0.94(P=0.35)$

2 Cystic periventricular leukomalacia

$\begin{array}{lc}\text { Lindner } 2005 & 2 / 31 \\ \text { Lista } 2015 & \text { 1/148 }\end{array}$

Subtotal (95\% CI)

179

Total events: 3 (Sustained inflations), 9 (Standard inflations)

Heterogeneity: Chi $^{2}=0.46, \mathrm{df}=\mathrm{I}(\mathrm{P}=0.50) ; \mathrm{I}^{2}=0.0 \%$

Test for overall effect: $Z=1.74(P=0.082)$

Test for subgroup differences: $\mathrm{Chi}^{2}=3.91, \mathrm{df}=\mathrm{I}(\mathrm{P}=0.05), \mathrm{I}^{2}=74 \%$

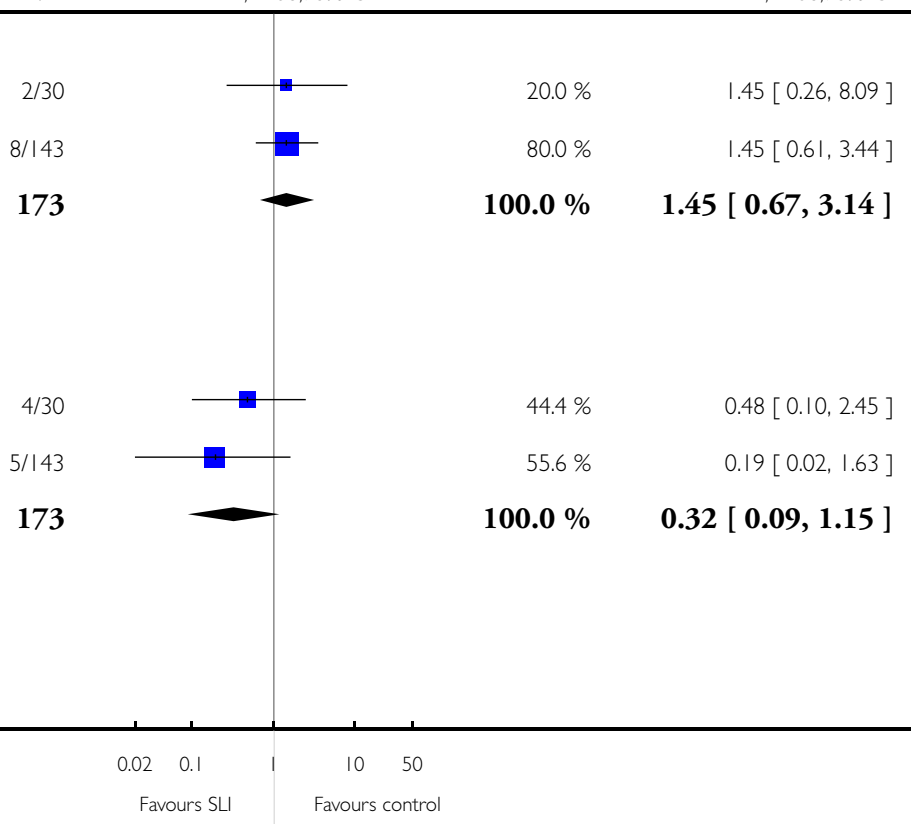

$8 / 143$

173 
Analysis I.I3. Comparison I Use of initial sustained inflations vs. standard inflations in newborns receiving resuscitation, Outcome 13 Retinopathy of prematurity (ROP).

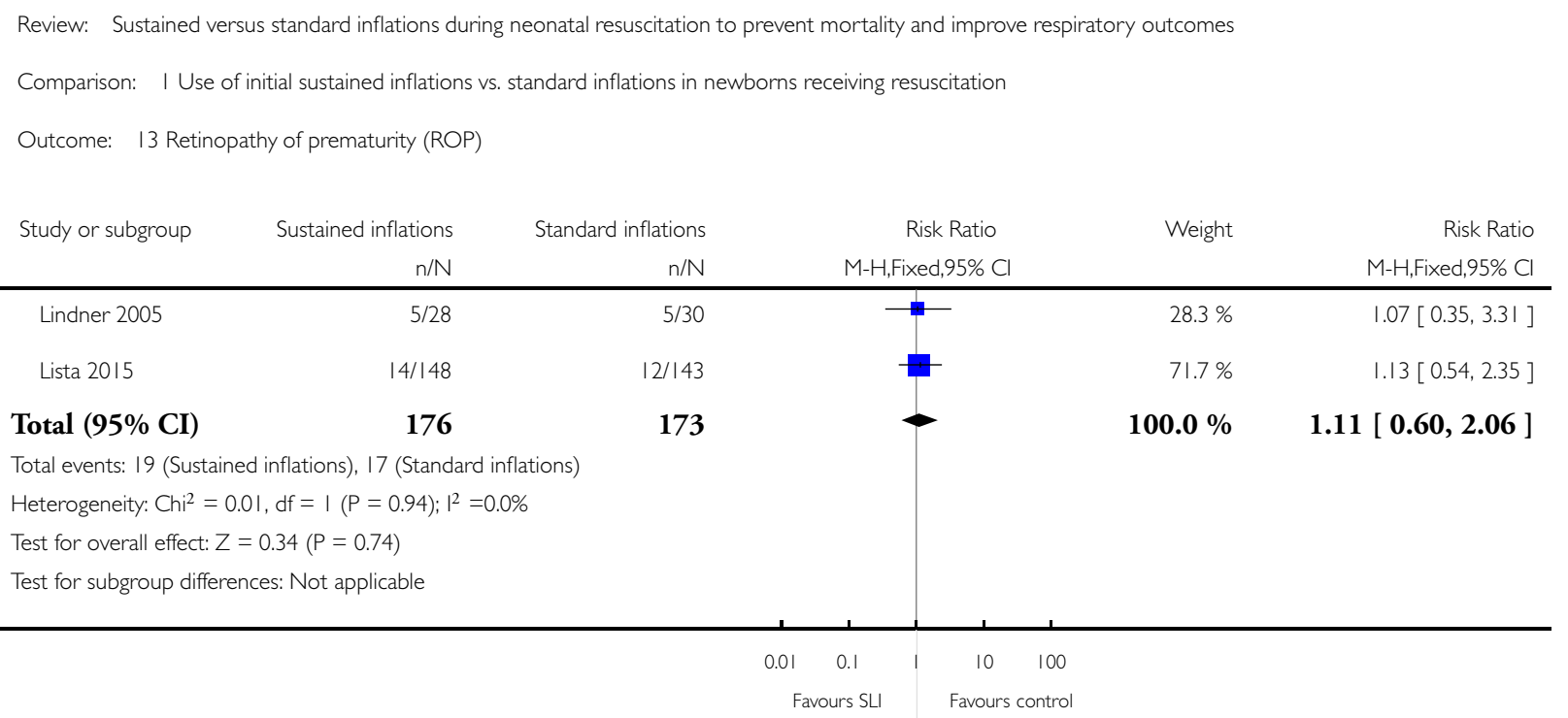


Analysis I.I4. Comparison I Use of initial sustained inflations vs. standard inflations in newborns receiving resuscitation, Outcome 14 Patent ductus arteriosus (PDA).

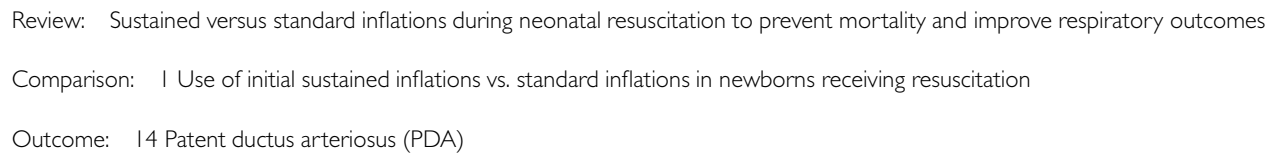

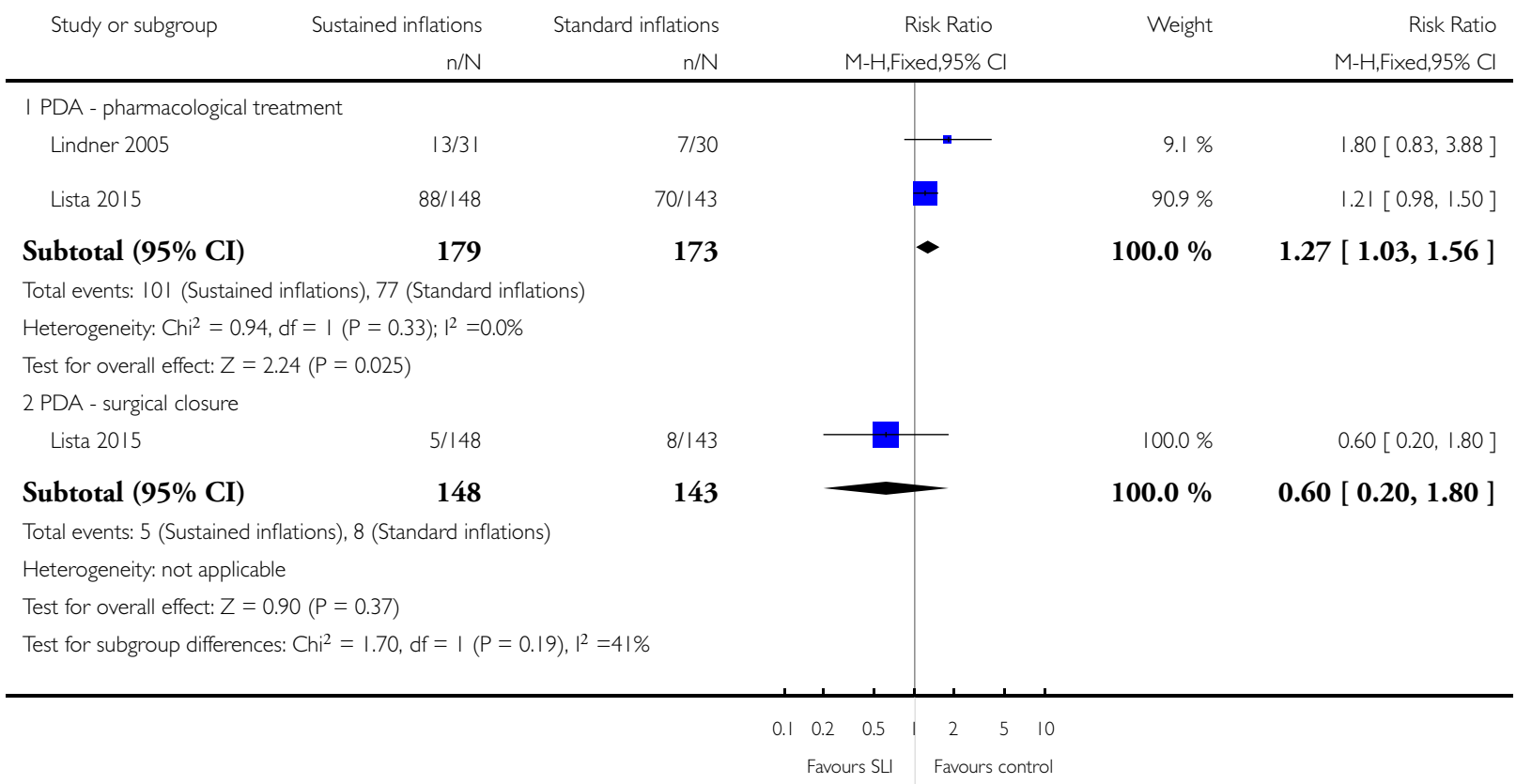

\section{H I S T O R Y}

Protocol first published: Issue 4, 2004

Review first published: Issue 7, 2015

\begin{tabular}{lll}
\hline Date & Event & Description \\
\hline 10 July 2008 & Amended & Converted to new review format. \\
\hline
\end{tabular}




\section{CONTRIBUTIONSOFAUTHORS}

Dr. O’Donnell and Dr Bruschettini performed the literature search, extracted and analysed the data and wrote the manuscript. Prof. Davis performed the literature search, extracted the data, checked the analysis and reviewed the manuscript. Prof. Morley and Dr Moja reviewed the manuscript. Dr. Calevo analysed the data, checked the analysis and reviewed the manuscript. Dr Zappettini performed the literature search, extracted the data and reviewed the manuscript.

\section{DECLARATIONSOF INTEREST}

COD, MB, PD, CM, LM, MC, and SZ have no known conflicts of interest to declare.

\section{SOURCES OF SUPPORT}

\section{Internal sources}

- Institute for Clinical Sciences, Lund University, Lund, Sweden.

- Royal Women's Hospital, Melbourne, Australia.

- University of Melbourne, Australia.

- Istituto Giannina Gaslini, Genoa, Italy.

\section{External sources}

- Murdoch Childrens Research Insitute, Australia.

- National Health and Medical Research Council, Australia.

- Eunice Kennedy Shriver National Institute of Child Health and Human Development National Institutes of Health, Department of Health and Human Services, USA.

- Editorial support of the Cochrane Neonatal Review Group has been funded with Federal funds from the Eunice Kennedy Shriver National Institute of Child Health and Human Development National Institutes of Health, Department of Health and Human Services, USA, under Contract No. HHSN275201100016C.

\section{DIFFERENCES BETWEEN PROTOCOLANDREVIEW}

We added clinically relevant outcomes (surfactant administration, need for mechanical ventilation, retinopathy of prematurity, and PDA).

We planned subgroup analyses according to gestational age ( $<37$ weeks, $\geq 37$ weeks), ventilation device used (self-inflating bag, flowinflating bag, T-piece, mechanical ventilator), patient interface used (face mask, ETT, nasopharyngeal tube) and duration of sustained inflation (> one second to five seconds, > five seconds). We were unable to conduct any subgroup analyses as only two trials met the inclusion criteria. 